Supporting Information for

\title{
Mechanochemical Ring-opening of Allylic Epoxides
}

Meredith H. Barbee, Junpeng Wang, Tatiana Kouznetsova, Meilin Lu, and Stephen L. Craig*

Department of Chemistry, Duke University, Durham NC, 27708

*to whom correspondence should be addressed: stephen.craig@duke.edu 


\section{Table of Contents}

General Information $\quad$ S3

Small Molecule Synthesis $\quad$ S5

$\begin{array}{ll}\text { Polymer Synthesis } & \text { S7 }\end{array}$

$\begin{array}{ll}\text { Stability of P1 Polymers } & \text { S10 }\end{array}$

Determining E/Z Ratio for P1 Polymers $\quad$ S12

Sonication of P1 Polymers $\quad \mathrm{S} 13$

$\begin{array}{ll}\text { Trapping Experiments } & \text { S16 }\end{array}$

Mechanochemically Induced Cross-Linking S23

$\begin{array}{lr}\text { Control Experiments } & \text { S28 }\end{array}$

Overlap Concentration Calculations $\quad$ S33

Single Molecule Force Spectroscopy $\quad$ S36

Rate Constant Calculation $\quad$ S42

Additional NMR Spectra $\quad$ S43

$\begin{array}{ll}\text { References } & \text { S49 }\end{array}$ 


\section{General Information}

\section{Reagents}

9-Oxabicyclo[6.1.0]non-4-ene, meta-chloroperoxybenzoic acid (77\%), cis,cis-1,3cyclooctadiene, Grubbs catalyst second generation, Quadrasil MP, 2,6-Di-tertbutyl-4-methylphenol, diisobutylaluminum hydride, 1-hexene, ethyl vinyl ether, 9phenanthrol, and HPLC grade THF were purchased from Sigma-Aldrich. $\mathrm{CHCl}_{2}$, hexanes, methanol, and ethyl acetate were purchased from VWR. $\mathrm{CDCl}_{3}$ was purchased from Cambridge Isotope Labs or Sigma-Aldrich. 9Oxabicyclo[6.1.0]non-4-ene and 1-hexene were distilled prior to use. All other reagents were used as received. Silicycle SiliaFlash® F60 gel (40-63 $\mu \mathrm{m}$ particle size, 230-400 mesh) and medium pressure liquid chromatography (MPLC) was performed on a Teledyne ISCO CombiFlash Rf 200.

\section{Instrumentation}

${ }^{1} \mathrm{H}$ NMR spectra were collected on either a $400 \mathrm{MHz}$ or $500 \mathrm{MHz}$ Varian NMR in $\mathrm{CDCl}_{3}$ and were referenced to $\mathrm{CDCl}_{3}(\delta=7.260) .{ }^{13} \mathrm{C} \mathrm{NMR}$ was collected on a $500 \mathrm{MHz}$ Varian NMR in $\mathrm{CDCl}_{3}$ and were referenced to $\mathrm{CDCl}_{3}(\delta=77.16)$.

Gel permeation chromatography (GPC) was preformed on with 2 Agilent PLgel $10^{5}$ $\AA$, $7.5 \times 300 \mathrm{~mm}, 5 \mu \mathrm{m}$ columns (part number PL1110-6550) at room temperature at a flow rate of $1.0 \mathrm{~mL} / \mathrm{min}$. The flow rate was set using Agilent 1260 Infinity Isocratic pump, molecular weights were calculated using in line Wyatt Optilab TrEX refractive index detector and Wyatt miniDAWN TREOS multi-angle light scattering detector, and UV absorbance was measured with an in line Agilent 1260 Infinity UV detector. The UV detector monitored 190 to $800 \mathrm{~nm}$ with step of 2.0 $\mathrm{nm}$ and slit width of $4.0 \mathrm{~nm}$. The refractive index increments for the polymers were determined by using $100 \%$ mass recovery assumption calculations built into Wyatt Astra software using solutions of known concentrations. Refractive index for small molecules was determined with the RI detector off-line. UV-vis experiments were conducted on a Varian Cary 50 Conc UV-Visible spectrometer and were referenced to a blank of pure THF in quartz cuvettes. High-resolution mass spectrometry was performed on an Agilent LCMS-TOF-DART at Duke University's Mass Spectrometry Facility.

\section{Sonication}

Ultrasound experiments were conducted with a Vibracell model VCZ500 at $20 \mathrm{kHz}$ sonicator. $13.1 \mathrm{~mm}$ replacable titanium tip probes (\#630-00007) with Suslick assembly (\#630-0224) and Suslick cells (\#830-00005) were purchased from Sonics and Materials, Inc. All experiments were conducted at $1 \mathrm{mg} / \mathrm{mL}$ in inhibitor free THF, 30\% amplitude, at an on 1 second off 1 second pattern, unless otherwise noted. Solutions were sparged with nitrogen or argon and cooled in an ice bath for 30 minutes prior to sonication. Positive pressure of inert gas and temperatures between $6-9^{\circ} \mathrm{C}$ were maintained throughout each experiment. Aliquots taken from 
sonication experiments were immediately ran on GPC without dilution, unless otherwise noted.

\section{SMFS Measurements}

The instrumentation and parameters used to collect data are similar to experiments conducted previously in the Craig group. ${ }^{1}$ Toluene was the solvent. Experiments were conducted at ambient temperature $\left(\sim 27^{\circ} \mathrm{C}\right)$ using a homemade Atomic Force Microscope (AFM), which is comprised of a Digital Instruments scanning head mounted on top of a piezoelectric positioner. Cantilever probes (Sharp Microlever silicon probes (MSNL), rectangular-shaped, $205 \mu \mathrm{m}, 15 \mu \mathrm{m}$, nominal tip radius $2 \mathrm{~nm}$, nominal spring constant $\mathrm{k} \sim 0.02 \mathrm{~N} / \mathrm{m}$, frequency $\sim 15 \mathrm{kHz}$ ) were purchased from Bruker (Camarillo, CA). The spring constants were determined in air for each probe with the thermal noise method described previously. ${ }^{2}$ The tip velocity for all experiments was $300 \mathrm{~nm} \mathrm{~s}^{-1}$. Force curve data was collected and analyzed using Matlab (The MathWorks, Inc., Natick, MA). All data were filtered during acquisition at $500 \mathrm{~Hz}$. After acquisition, the data was calibrated and plotted with software written in Matlab. 


\section{Small Molecule Synthesis}

(Z)-9-oxabicyclo[6.1.0]non-2-ene (epoxyCOD) (1)

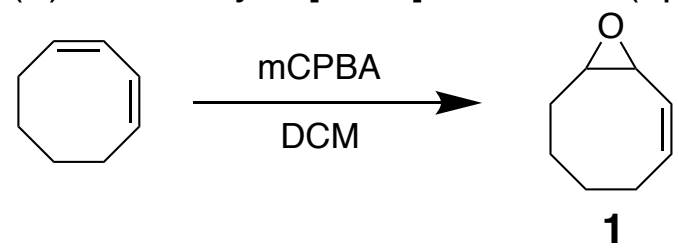

A solution of meta-chloroperoxybenzoic acid (77\%, 14.41g, $643 \mathrm{mmol}, 1$ equiv) in dichloromethane $(50 \mathrm{~mL})$ was added dropwise to a solution of cis,cis-1,3cyclooctadiene $(8.0 \mathrm{~mL}, 643 \mathrm{mmol}, 1$ equiv) in dichloromethane $(50 \mathrm{~mL})$ in an ice bath over 45 minutes. The reaction was allowed to warm to room temperature and stirred overnight. Aqueous sodium bisulfite was added to quench the reaction then the white solid was removed by filtration. The remaining solution was washed with sodium bisulfite, sodium bicarbonate, and brine, dried with sodium sulfate, then purified by silica flash chromatography (hexane to $5 \%$ ethyl acetate in hexane). The pure product was collected from vacuum distillation at $40^{\circ} \mathrm{C}$ to yield $1(3.86 \mathrm{~g}$, $48.2 \%$ yield) as a clear colorless oil.

${ }^{1} \mathrm{H}$ NMR $\left(\mathrm{CDCl}_{3}, 400 \mathrm{MHz}\right) \delta 5.77$ (dddd, $\mathrm{J}=11.2,7.1,5.6,1.2 \mathrm{~Hz}, 1 \mathrm{H}$ ), 5.59 (dq, $\mathrm{J}=11.2,1.3 \mathrm{~Hz}, 1 \mathrm{H}), 3.45(\mathrm{dt}, \mathrm{J}=3.9,1.2 \mathrm{~Hz}, 1 \mathrm{H}), 3.11$ (dtd, $\mathrm{J}=9.2,3.9,1.0 \mathrm{~Hz}$, $1 \mathrm{H}), 2.31(\mathrm{~m}, 1 \mathrm{H}), 2.18-1.94(\mathrm{~m}, 2 \mathrm{H}), 1.86-1.71(\mathrm{~m}, 1 \mathrm{H}), 1.71-1.60(\mathrm{~m}, 2 \mathrm{H})$, $1.52-1.34(\mathrm{~m}, 2 \mathrm{H}) .{ }^{13} \mathrm{C}$ NMR $\left(126 \mathrm{MHz}, \mathrm{CDCl}_{3}\right) \delta 134.49,122.67,58.23,53.84$, 29.18, 27.42, 25.69, 25.27.

HRMS (m/z): $[\mathrm{M}+\mathrm{H}]+$ Calculated for $\mathrm{C}_{8} \mathrm{H}_{12} \mathrm{O}$ 125.09609, Observed 125.09579

(Z)-cyclooct-4-en-1-ol (2)
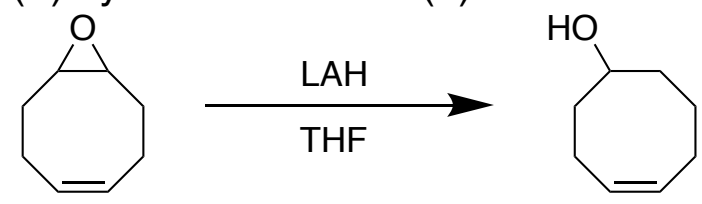

2

Monomer 2 was synthesized according to a literature procedure. ${ }^{3}$

${ }^{1} \mathrm{H}$ NMR $\left(\mathrm{CDCl}_{3}, 400 \mathrm{MHz}\right) \delta 5.74-5.54(\mathrm{~m}, 1 \mathrm{H}), 3.85-3.78(\mathrm{~m}, 1 \mathrm{H}), 2.29$ (ddt, $\mathrm{J}=18.3,9.2,4.0 \mathrm{~Hz}, 1 \mathrm{H}), 2.19-2.05(\mathrm{~m}, 3 \mathrm{H}), 1.98-1.80(\mathrm{~m}, 2 \mathrm{H}), 1.76-1.45$ $(\mathrm{m}, 4 \mathrm{H}) .{ }^{13} \mathrm{C} \mathrm{NMR}\left(126 \mathrm{MHz}, \mathrm{CDCl}_{3}\right) \delta 130.28,129.68,72.87,37.86,36.41,25.79$, 25.00, 22.91.

HRMS (m/z): $[\mathrm{M}+\mathrm{H}]+$ Calculated for $\mathrm{C}_{8} \mathrm{H}_{14} \mathrm{O}$ 127.1117, Observed 127.1116 
9-methoxyphenanthrene

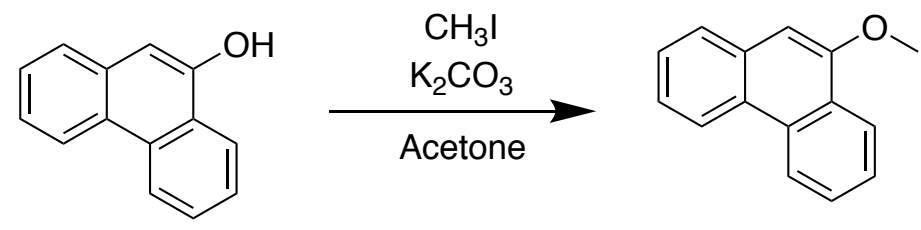

The model small molecule 9-methoxyphenanthrene was synthesized according to a literature procedure with the following modifications. ${ }^{4}$ 9-phenanthanol $(4.0 \mathrm{~g}, 1$ equiv, $20.59 \mathrm{mmol})$ and potassium carbonate $(4.27 \mathrm{~g}, 1.5$ equiv, $30.89 \mathrm{mmol})$ were refluxed in acetone $(20 \mathrm{~mL})$ for 1 hour. Methyl iodide $(2.56 \mathrm{~mL}, 2$ equiv, 41.18 $\mathrm{mmol}$ ) was added dropwise and refluxed overnight. The reaction progress was monitored by TLC and up to 1 additional equivalent of methyl iodide was added as necessary. After 18 hours, the reaction mixture was cooled, added to ethyl acetate, and washed with water 3 times, then brine, then dried with sodium sulfate. The mixture was then dried onto silica, then eluted from the column in pure hexane. The resulting white solid was recrystallized from boiling methanol to give 9methoxyphenanthrene as flaky white crystals $(1.98 \mathrm{~g}, 46.1 \%)$.

${ }^{1} \mathrm{H} \mathrm{NMR}\left(\mathrm{CDCl}_{3}, 500 \mathrm{MHz}\right) \delta 8.68(\mathrm{~d}, \mathrm{~J}=8.1 \mathrm{~Hz}, 1 \mathrm{H}), 8.62(\mathrm{~d}, \mathrm{~J}=8.0 \mathrm{~Hz}, 1 \mathrm{H})$, $8.43(\mathrm{~d}, \mathrm{~J}=8.0 \mathrm{~Hz}, 1 \mathrm{H}), 7.81(\mathrm{~d}, \mathrm{~J}=7.7 \mathrm{~Hz}, 1 \mathrm{H}), 7.68(\mathrm{dt}, \mathrm{J}=15.0,7.8 \mathrm{~Hz}, 2 \mathrm{H})$, $7.56(\mathrm{dt}, \mathrm{J}=22.9,7.2 \mathrm{~Hz}, 2 \mathrm{H}), 7.01(\mathrm{~s}, 1 \mathrm{H}), 4.10(\mathrm{~s}, 3 \mathrm{H}) .{ }^{13} \mathrm{C} \mathrm{NMR}(126 \mathrm{MHz}$, $\left.\mathrm{CDCl}{ }^{3}\right) \delta 153.64,133.03,131.36,127.42,127.24,126.98,126.68,126.58,126.49$, 124.33, 122.64, 102.03, 55.52.

HRMS (m/z): $[\mathrm{M}+\mathrm{H}]+$ Calculated for $\mathrm{C}_{15} \mathrm{H}_{12} \mathrm{O} 209.09609$, Observed 209.09603 


\section{Polymer Synthesis}

High Molecular Weight P1 Polymers

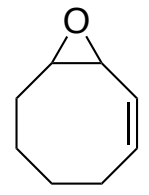

1

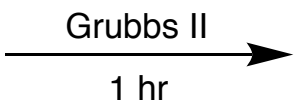

P1

A stock solution of Grubbs second generation catalyst (100 $\mu \mathrm{L}, 0.6 \mathrm{mg}, 0.0007$ mmol, 1 equiv) in dichloromethane was charged to monomer 1 (150 mg, 1.208 mmol, 1700 eqiv) in a scintillation vial. Additional DCM was added as necessary to maintain stirring. After 45 minutes, 3-4 $\mathrm{mL}$ of ethyl vinyl ether that had been previously purified by passing through silica was added to quench the reaction. Quadrasil $(9.0 \mathrm{mg}, 0.0134 \mathrm{mmol}, 200$ equiv) was added and the mixture was stirred overnight. Then the reaction was filtered through a celite plug and the polymer precipitated in cold methanol 3 times to yield $\mathbf{P 1}$ as a white solid (21.1 $\mathrm{mg}$ ). See Figure S6 for a representative ${ }^{1} \mathrm{H}$ NMR and Figure S5 for the 90 degree light scattering detector trace.

Low Molecular Weight P1 Polymers

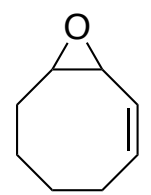

1

1

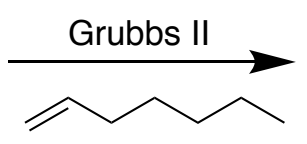

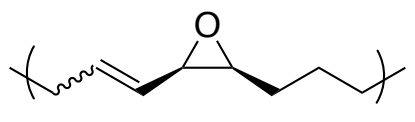

P1

1-hexene (23.5mg, $0.280 \mathrm{mmol}, 28$ equiv) was charged to monomer $1(2.250 \mathrm{~g}$, $18.1 \mathrm{mmol}, 1700$ eqiv) in a scintillation vial. A stock solution of Grubbs second generation catalyst (100 $\mu \mathrm{L}, 9 \mathrm{mg}, 0.010 \mathrm{mmol}, 1$ equiv) in dichloromethane was added. DCM was added as necessary to maintain stirring and the reaction was ran over night. 3-4 $\mathrm{mL}$ of ethyl vinyl ether that had been previously purified by passing through silica was added. After 1 hour, the polymer was precipitated into cold methanol and centrifuged 3 times to yield $176 \mathrm{mg}$ of $\mathbf{P} 1$ as a clear oil. See Figure S25 for a representative ${ }^{1} \mathrm{H}$ NMR and Figure S26 for the 90 degree light scattering detector trace. 
High Molecular Weight P2 Polymers

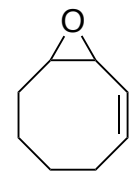

1

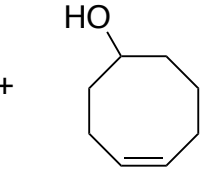

2

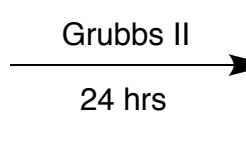

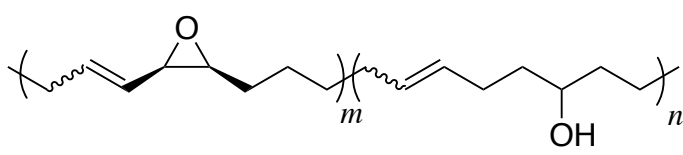

P2

Monomer 1 (70.7 $\mathrm{mg}, 0.570 \mathrm{mmol}, 850$ equiv) was charged to a flask with monomer 2 (71.9 mg, $0.570 \mathrm{mmol}, 850$ equiv). A stock solution of Grubbs second generation catalyst ( $100 \mu \mathrm{L}, 0.6 \mathrm{mg}, 0.0007 \mathrm{mmol}, 1$ equiv) was added. After 10 minutes, $0.5 \mathrm{~mL}$ of DCM was added. The viscosity was monitored and additional DCM added as necessary to keep the solution stirring. After 15 hours, 3-4 mL of ethyl vinyl ether that had been previously purified by passing through silica was added and the reaction was stirred for 1 hour. The polymer was purified by precipitating 3 times in methanol to yield $\mathbf{P 2}$ as a white solid $(70.7 \mathrm{mg})$. See Figure S19 for a representative ${ }^{1} \mathrm{H}$ NMR and Figure S20 for the 90 degree light scattering detector trace.

Low Molecular Weight P2 Polymers

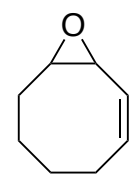

1

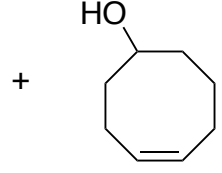

2

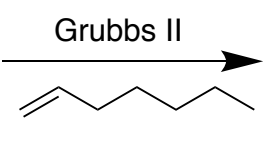

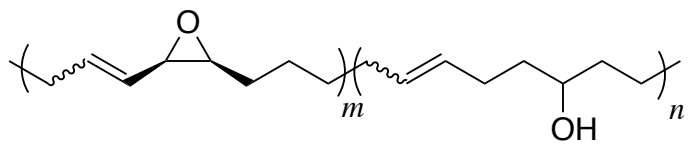

P2

Monomer 1 ( $1.12 \mathrm{~g}, 9.0 \mathrm{mmol}, 850$ equiv) was charged to a flask with monomer 2 (1.14 g, $9.0 \mathrm{mmol}, 850$ equiv) and 1 -hexene $(27.1 \mathrm{mg}, 0.321 \mathrm{mmol}, 28$ equiv). A stock solution of Grubbs second generation catalyst $(200 \mu \mathrm{L}, 9.0 \mathrm{mg}, 0.01 \mathrm{mmol}$, 1 equiv) was added. DCM was added as necessary to maintain stirring and the reaction was ran over night. 3-4 $\mathrm{mL}$ of ethyl vinyl ether that had been previously purified by passing through silica was added. After 1 hour, the polymer was precipitated into cold methanol and centrifuged 3 times to give $549 \mathrm{mg}$ of P2 as a clear oil. See Figure S29 for a representative ${ }^{1} \mathrm{H}$ NMR and Figure S28 for the 90 degree light scattering detector trace. 


\section{P3 Polymers}<smiles></smiles>

1<smiles>ClC1(Cl)C2CC=CCCC21</smiles>

3

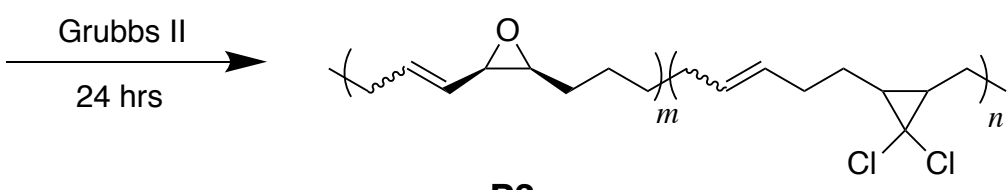

P3

Monomer 1 (71 mg, $0.570 \mathrm{mmol}, 850$ equiv) was charged to a flask with monomer 2 (109 mg, $0.570 \mathrm{mmol}, 850$ equiv). A stock solution of Grubbs second generation catalyst (200 $\mu \mathrm{L}, 9.0 \mathrm{mg}, 0.01 \mathrm{mmol}, 1$ equiv) was added. DCM was added as necessary to maintain stirring and the mixture was stirred overnight. $3-4 \mathrm{~mL}$ of ethyl vinyl ether that had been previously purified by passing through silica was added. After 1 hour, the polymer was precipitated into cold methanol 3 times to give $87.6 \mathrm{mg}$ of $\mathbf{P 3}$ as a white solid. See Figure S36 for a representative ${ }^{1} \mathrm{H}$ NMR and Figure S34 for the refractive index detector trace and 90 degree light scattering detector trace. 


\section{Stability of P1 Polymers}

Numerous polymers were made throughout this study. Whenever possible, polymers were sonicated on the same day as they were prepared to avoid degradation and cross-linking. Occasionally polymers were stored in THF solution overnight in a flammable safe refrigerator prior to sonication. Polymers crosslinked quickly when stored dry, and initial attempts to purify polymers by precipitation alone were not as successful as those with added Quadrasil. The molecular weights of $\mathbf{P 1}$ polymers in particular were higher than predicted based on the ratio of catalyst to monomer, indicating that some cross-linking and branching has occurred.

To determine the stability of a $\mathbf{P} \mathbf{1}_{\text {polymer over time, }} \mathbf{P} \mathbf{1}_{125}$ was synthesized and left at room temperature in a THF solution for 48 hours. The retention time of the polymer did shift over this time period (Figure S1). The calculated molecular weight of the polymer does decrease between 24 and 48 hours after preparation. After this time, molecular weight determination is complicated by precipitation of the polymer (Table S1). ${ }^{1} \mathrm{H}$ NMR shows no indication of isomerization (Figure S2) after 48 hours. The polymers in this study were sonicated within 24 hours of preparation.

Table S1: Stability of $\mathbf{P} 1_{125}$ over 48 hours.

\begin{tabular}{lllll}
\hline Time (hours) & Polymer & Mn (kDa) & Mw (kDa) & PDI \\
\hline $\mathbf{0}$ & $\mathrm{P} 1_{125}$ & 126 & 219 & 1.73 \\
$\mathbf{2 4}$ & $\mathrm{P} 1_{125}$ & 125 & 198 & 1.58 \\
$\mathbf{4 8}$ & $\mathrm{P} 1_{125}$ & 52 & 99 & 1.89 \\
\hline
\end{tabular}

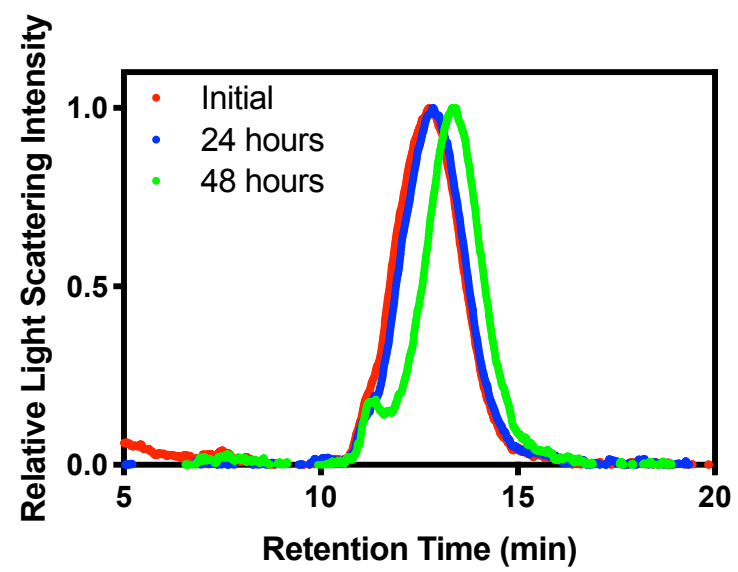

Figure S1: Relative light scattering intensity for $\mathbf{P} \mathbf{1}_{125}$ for the 90 degree detector shortly after purification (red), after 24 hours (blue), and after 48 hours (green). 


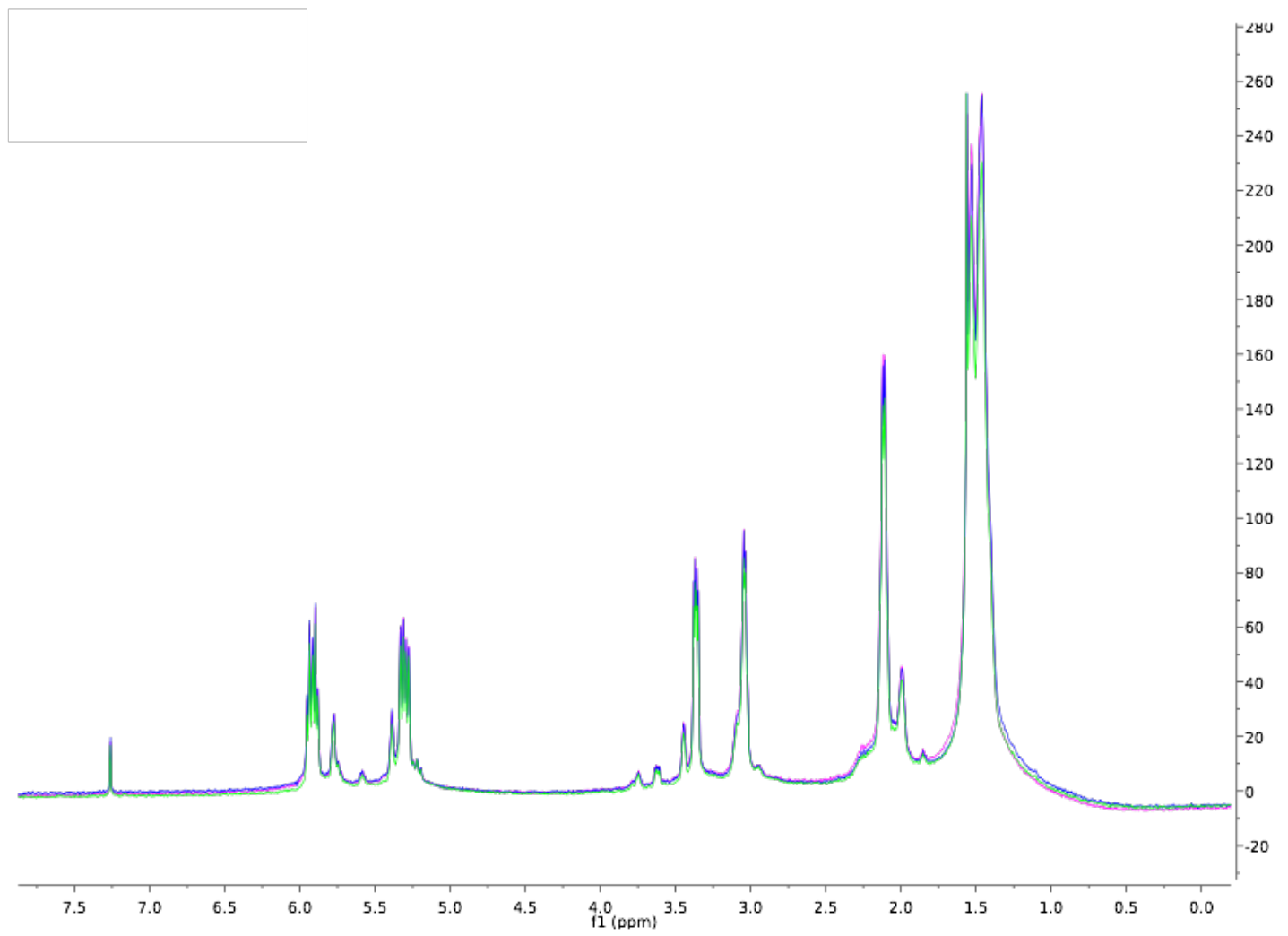

Figure S2: ${ }^{1} \mathrm{H} \mathrm{NMR}\left(400 \mathrm{MHz}, \mathrm{CDCl}_{3}\right.$ ) of $\mathbf{P} \mathbf{1}_{125}$ immediately after purification (pink), after 24 hours (blue), and after 48 hours (green). 


\section{Determining E/Z Ratio of P1 Polymers}

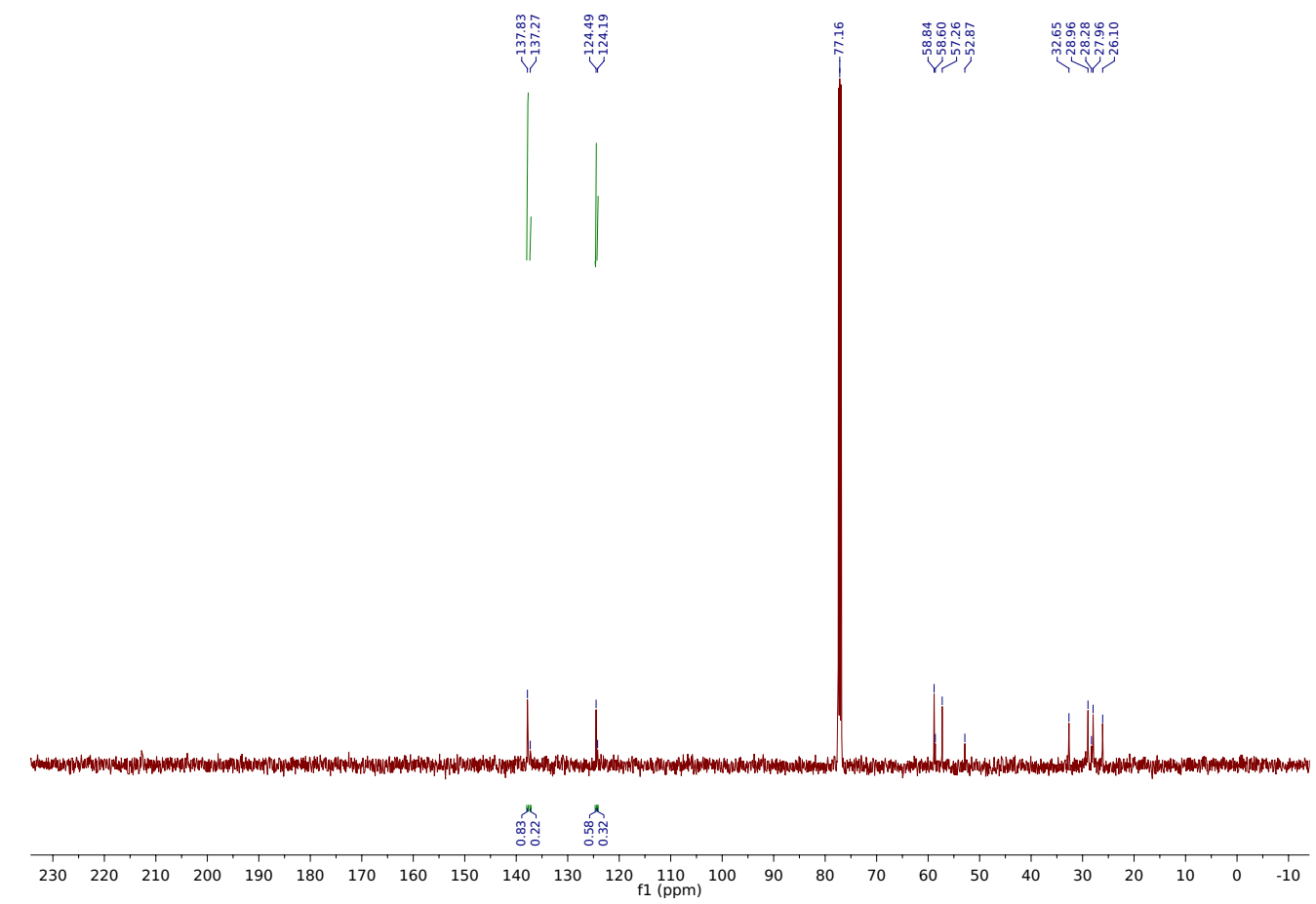

Figure S3: The full ${ }^{13} \mathrm{C}$ NMR $\left(\mathrm{CDCl}_{3}, 100 \mathrm{MHz}\right)$ of $\mathbf{P} 1_{590}$.
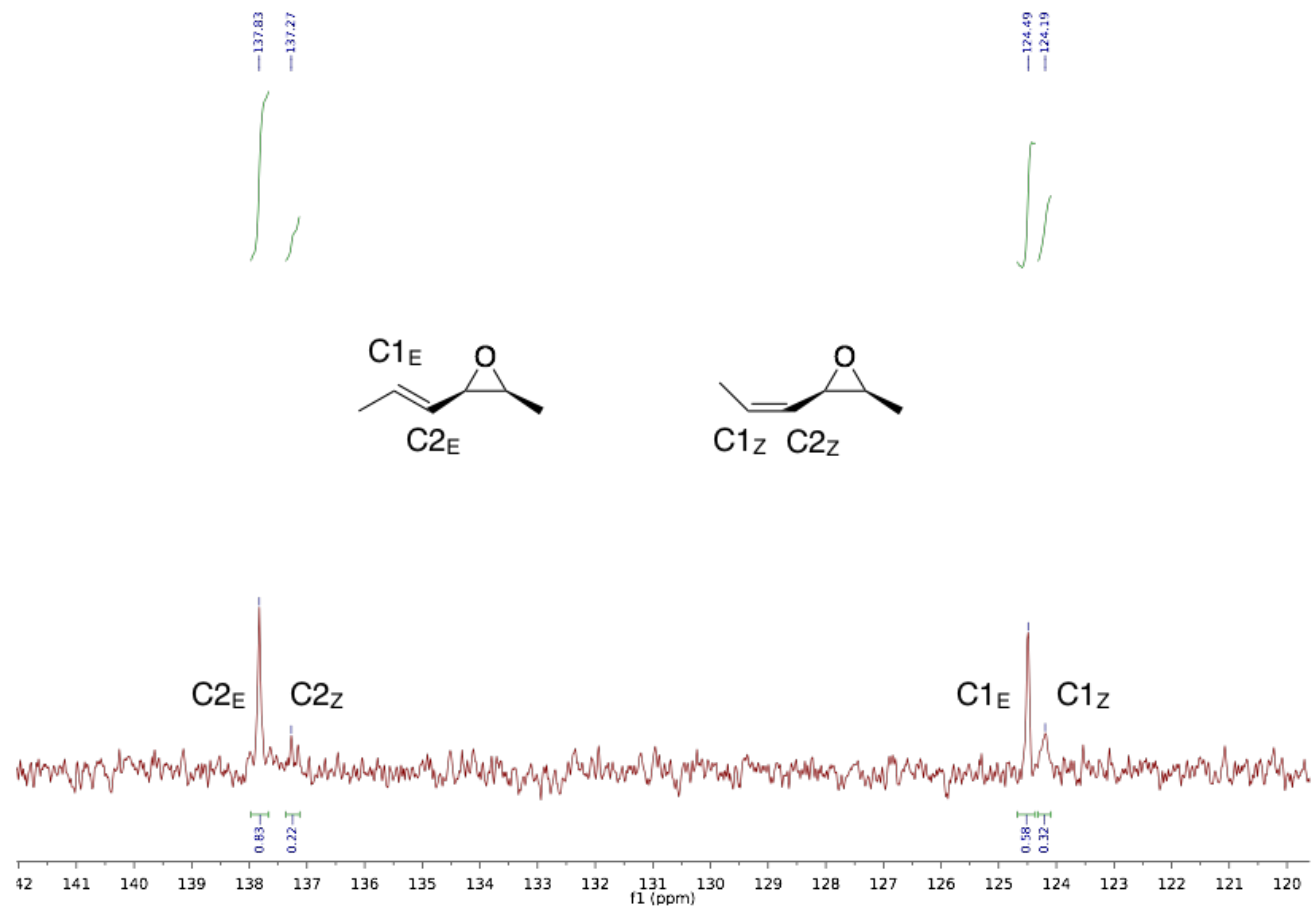

Figure S4: A region of the ${ }^{13} \mathrm{C}$ NMR from Figure S3. The peak assignments used to determine the $E / Z$ ratio are shown. The $E / Z$ ratio is the average of $C 2_{E} / C 2 z$ and $C 1_{E} / C 2 z$. 


\section{Sonication of P1 Polymers}

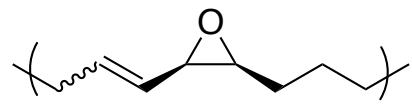

P1

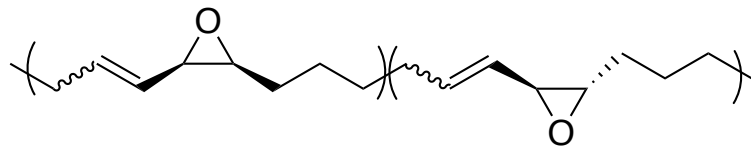

Polymer P1590 was sonicated in THF at a concentration of $1.0 \mathrm{mg} / \mathrm{mL}$ under standard conditions. After sonication, the solvent was removed by rotary evaporation to collect the sonicated polymer.
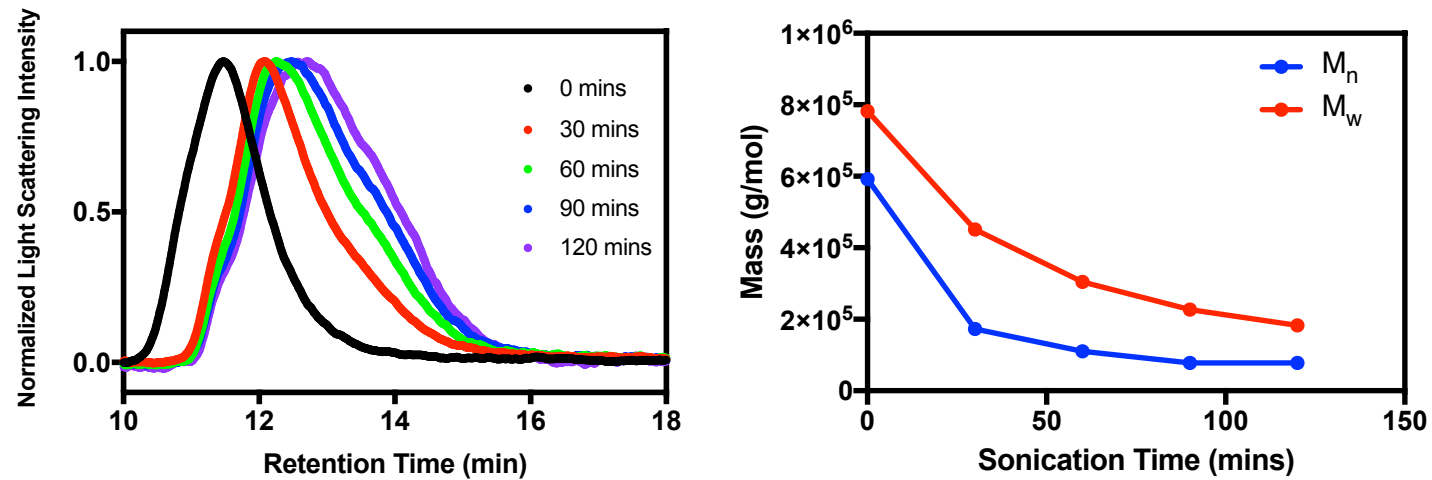

Figure S5: GPC traces (left) and calculated molecular weights (right) after every 30 minutes of sonication time for $\mathbf{P 1}$ 590. (MB_3_24)

Percent Isomerization of $P 1_{590}$ by ${ }^{1} \mathrm{H}$ NMR

$\%$ trans epoxide $=\left(\left(\mathrm{H}_{\text {trans }}\right) /\left(\mathrm{H}_{\text {vinyl }}\right)\right)^{*} 100=20.8 \%$

$H_{\text {vinyl }}=\int 5.41-4.93=1.87$

$H_{\text {trans }}=\int 2.75-2.85=0.39$

Percent Isomerization per scission cycle

A scission cycle is defined by equation $\mathrm{S} 1$. Percent isomerization is defined by equation S2.

$$
\begin{aligned}
& \text { Scission cycle }=\frac{\ln \left(\text { initial } M_{n}\right)-\ln \left(\text { final }_{M_{n}}\right)}{\ln 2} \\
& \% \text { Isomerization }=\frac{\% \text { Isomerization by } N M R}{\text { scission cycle }}
\end{aligned}
$$




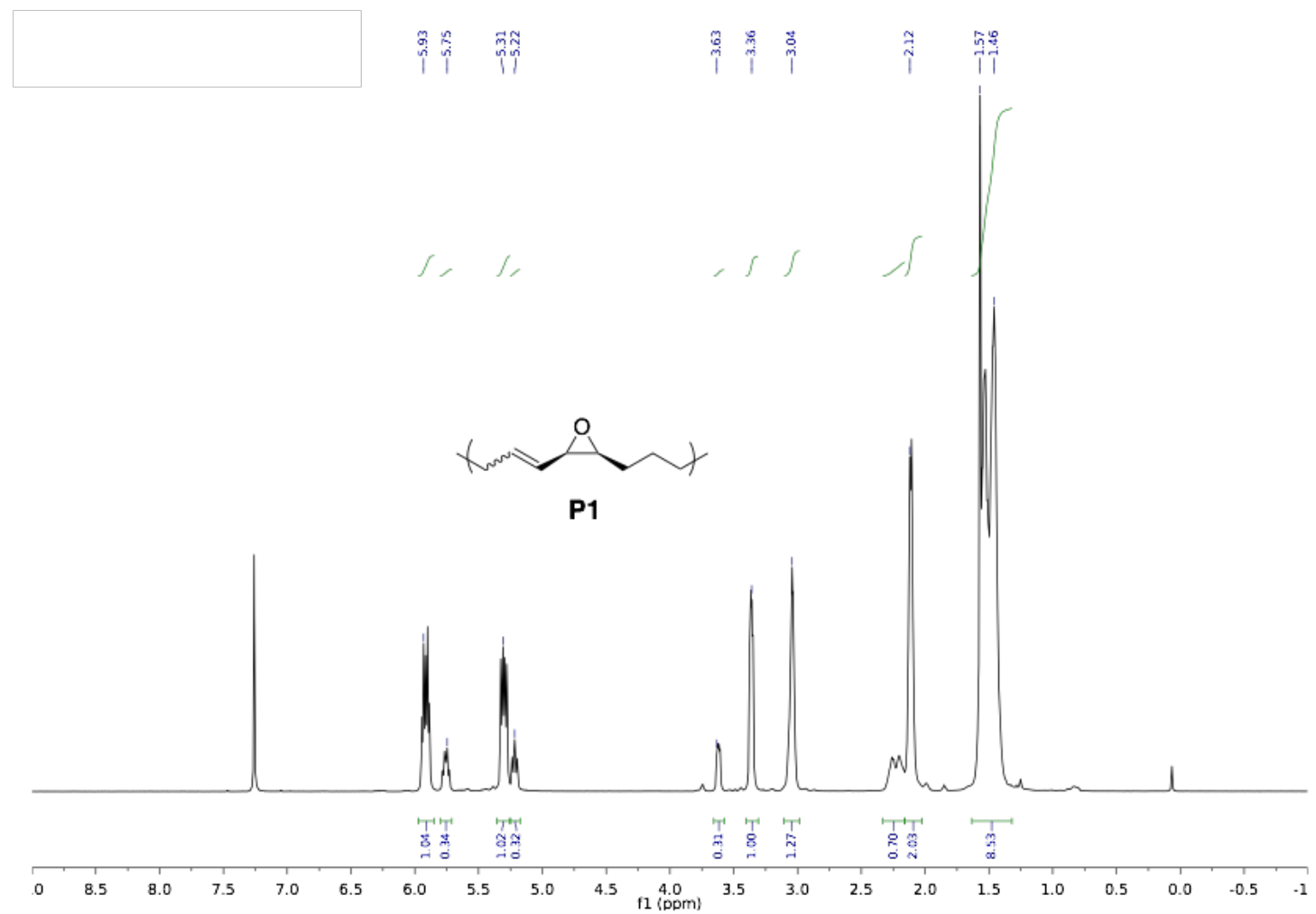

Figure S6: ${ }^{1} \mathrm{H}$ NMR (500 MHz, $\mathrm{CDCl}_{3}$ ) of $\mathbf{P} 1_{590}$ prior to sonication.

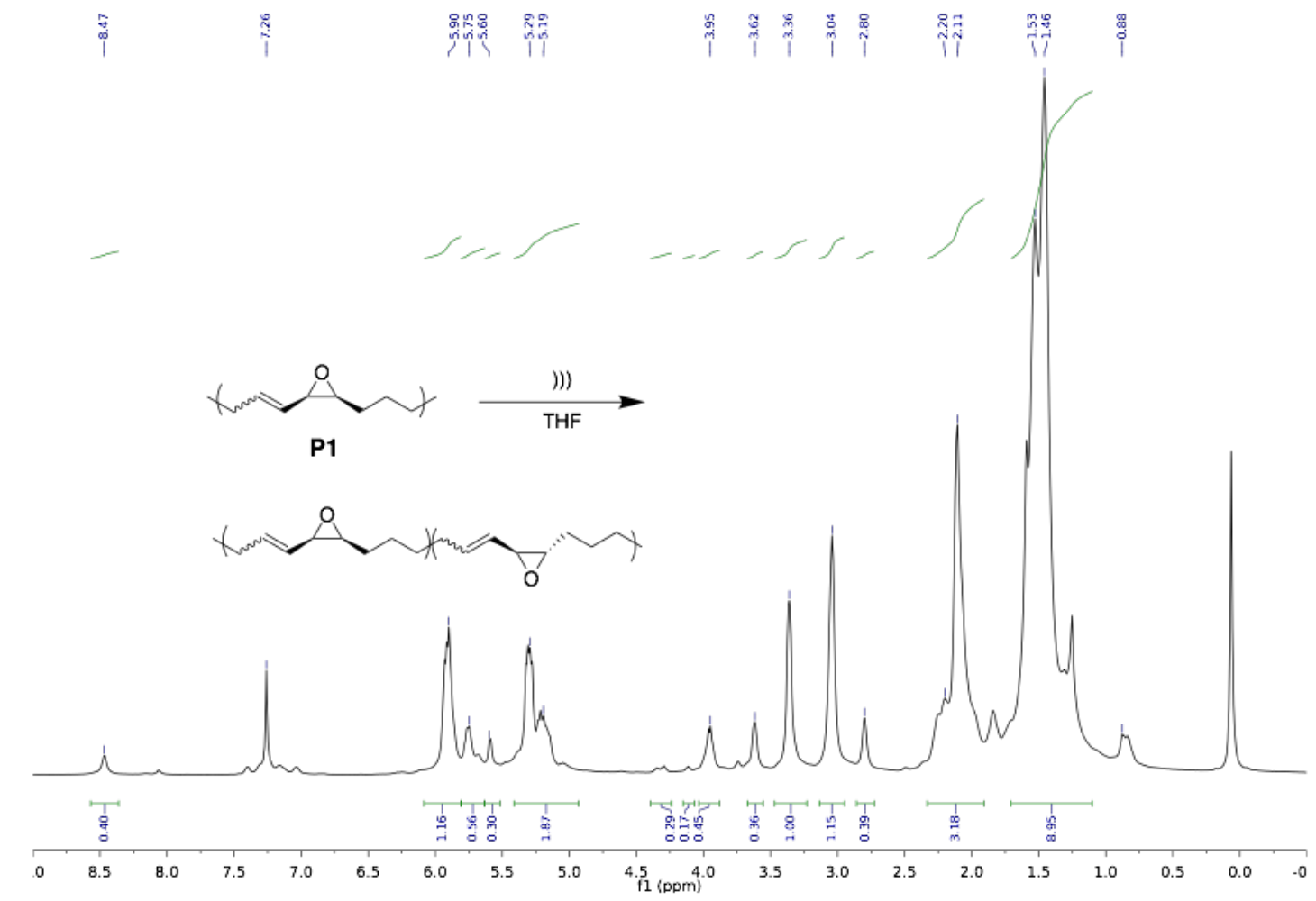

Figure S7: ${ }^{1} \mathrm{H}$ NMR $\left(500 \mathrm{MHz}, \mathrm{CDCl}_{3}\right)$ of $\mathbf{P} 1_{590}$ after sonication. 


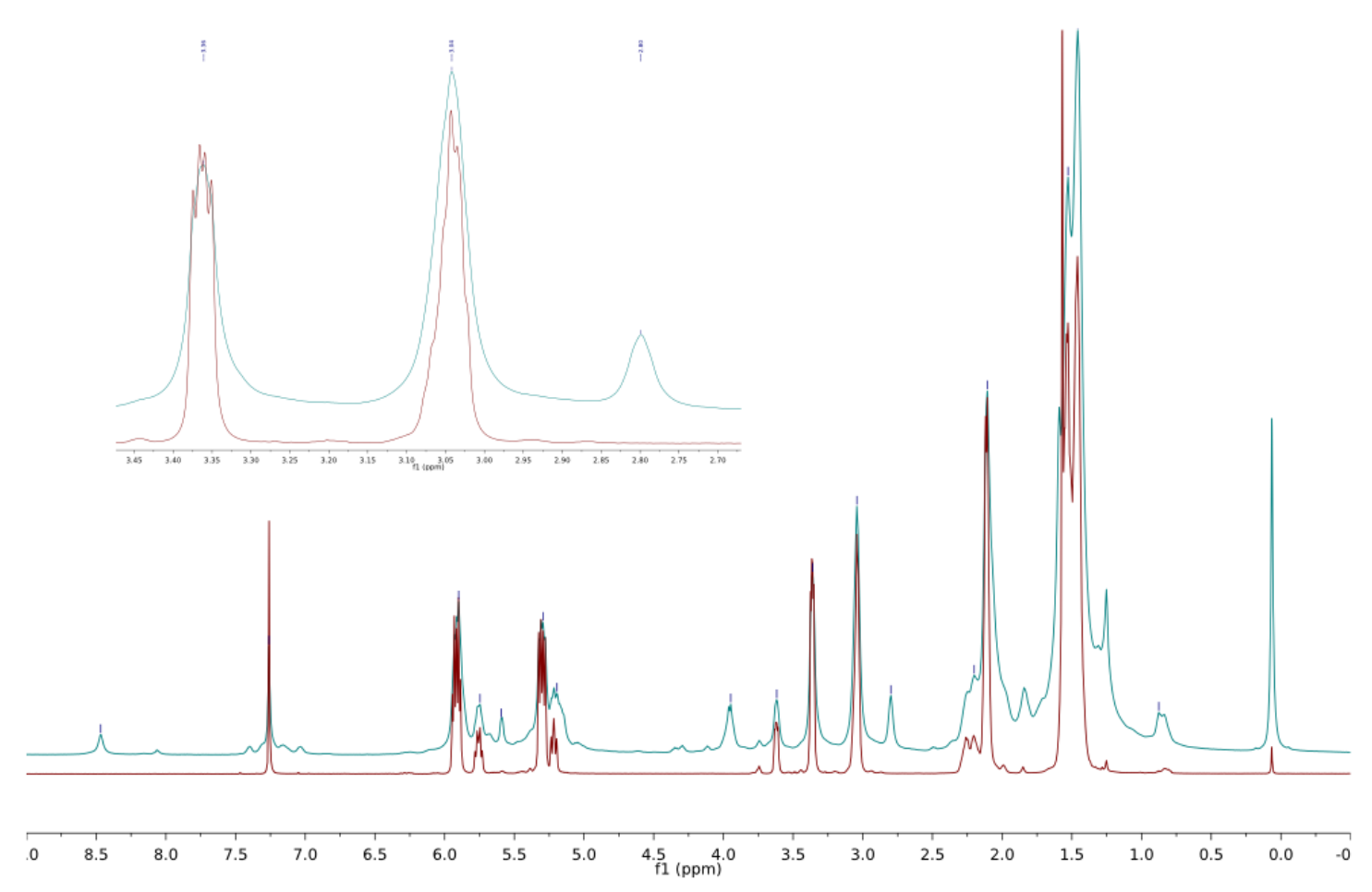

Figure S8: ${ }^{1} \mathrm{H}$ NMR (500 MHz, $\mathrm{CDCl}_{3}$ ) of $\mathbf{P} 1_{590}$ before sonication (red) and after sonication (blue). The inlay shows the region with the resonance corresponding to the new trans-epoxide resonance.

Table S2: Average isomerization per scission cycle for duplicate $\mathbf{P 1}$ polymers

\begin{tabular}{|c|c|c|c|}
\hline Name & $M_{n}(k D a)$ & Final $M_{n}(k D a)$ & $\begin{array}{l}\text { \% Isomerization } \\
\text { per scission cycle }\end{array}$ \\
\hline P1590 ${ }^{a}$ & 592 & 78 & 6.8 \\
\hline$P 1_{590} b$ & 589 & 83 & 4.0 \\
\hline $\mathrm{P} 1{ }_{150^{c}}$ & 152 & 45 & 8.3 \\
\hline average & & & 6.4 \\
\hline std dev & & & 2.2 \\
\hline
\end{tabular}

a. This is the same polymer $\mathrm{P} 1590$ as in Table 1.

b. This is a duplicate of $\mathrm{P} 1590$

c. This polymer was sonicated for 60 minutes instead of 120 minutes. 


\section{Trapping Experiments}

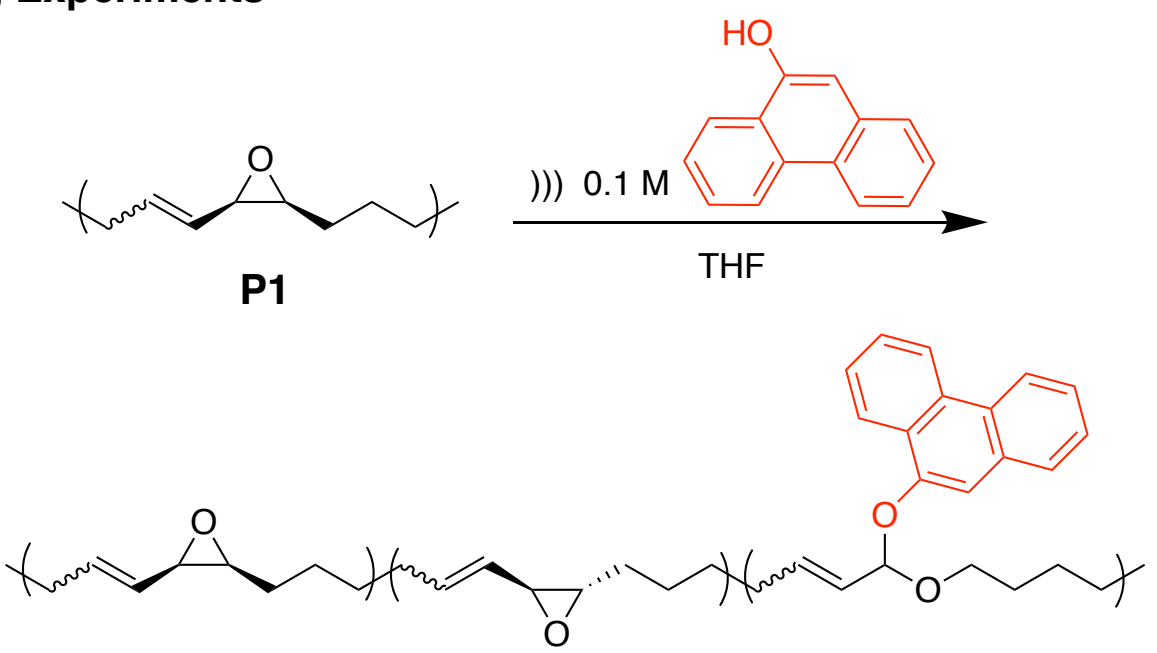

Polymer $\mathbf{P} 1_{590}$ was dissolved in a solution of 0.1M 9-phenantrol in tetrahydrofuran (THF) and sonicated under standard conditions. After sonication, the solution was concentrated and precipitated twice into cold methanol to collect the sonicated polymer.

\section{Percent trapping by ${ }^{1} \mathrm{H} N M R$}

$\%$ trans epoxide $=\left(\mathrm{H}_{\text {trans }}\right) /\left(\mathrm{H}_{\text {vinyl }}\right)=17.6 \%$

$\%$ trapping $=\left(\mathrm{H}_{\text {aromatic }} / 9\right) /\left(\mathrm{H}_{\text {vinyl }}\right)=18.4 \%$

$\mathrm{H}_{\text {aromatic }}=\int 7.3-8.1=2.54$

$H_{\text {vinyl }}=\int 5.41-4.93=1.53$

$H_{\text {trans }}=\int 2.75-2.85=0.27$ 


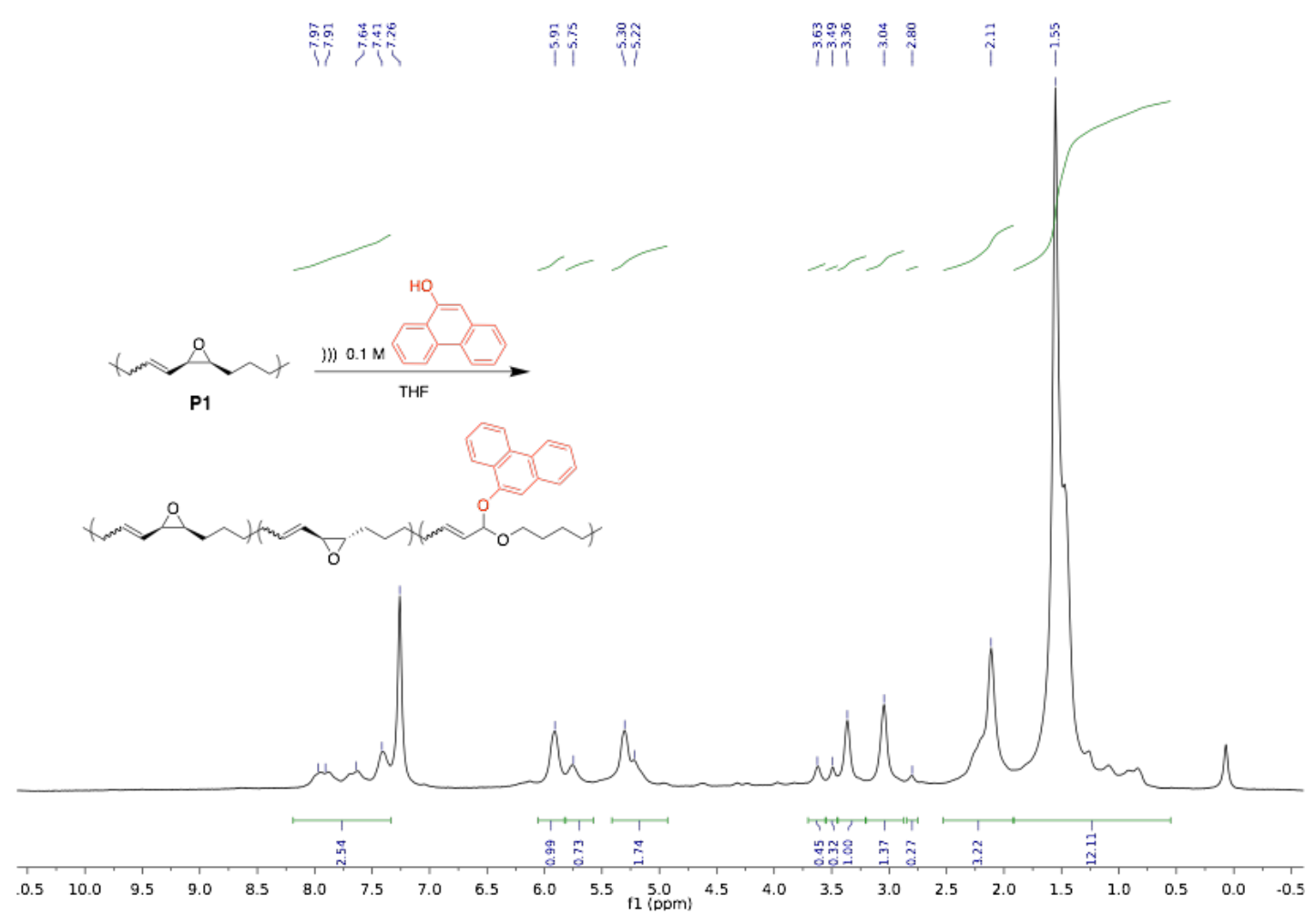

Figure S9: ${ }^{1} \mathrm{H}$ NMR $\left(500 \mathrm{MHz}, \mathrm{CDCl}_{3}\right.$ ) after sonication of $\mathbf{P} \mathbf{1}_{590}$ in the presence of 9-phenanthrol. A ${ }^{1} \mathrm{H}$ NMR of $\mathbf{P} 1_{590}$ prior to sonication is shown in Figure S6.

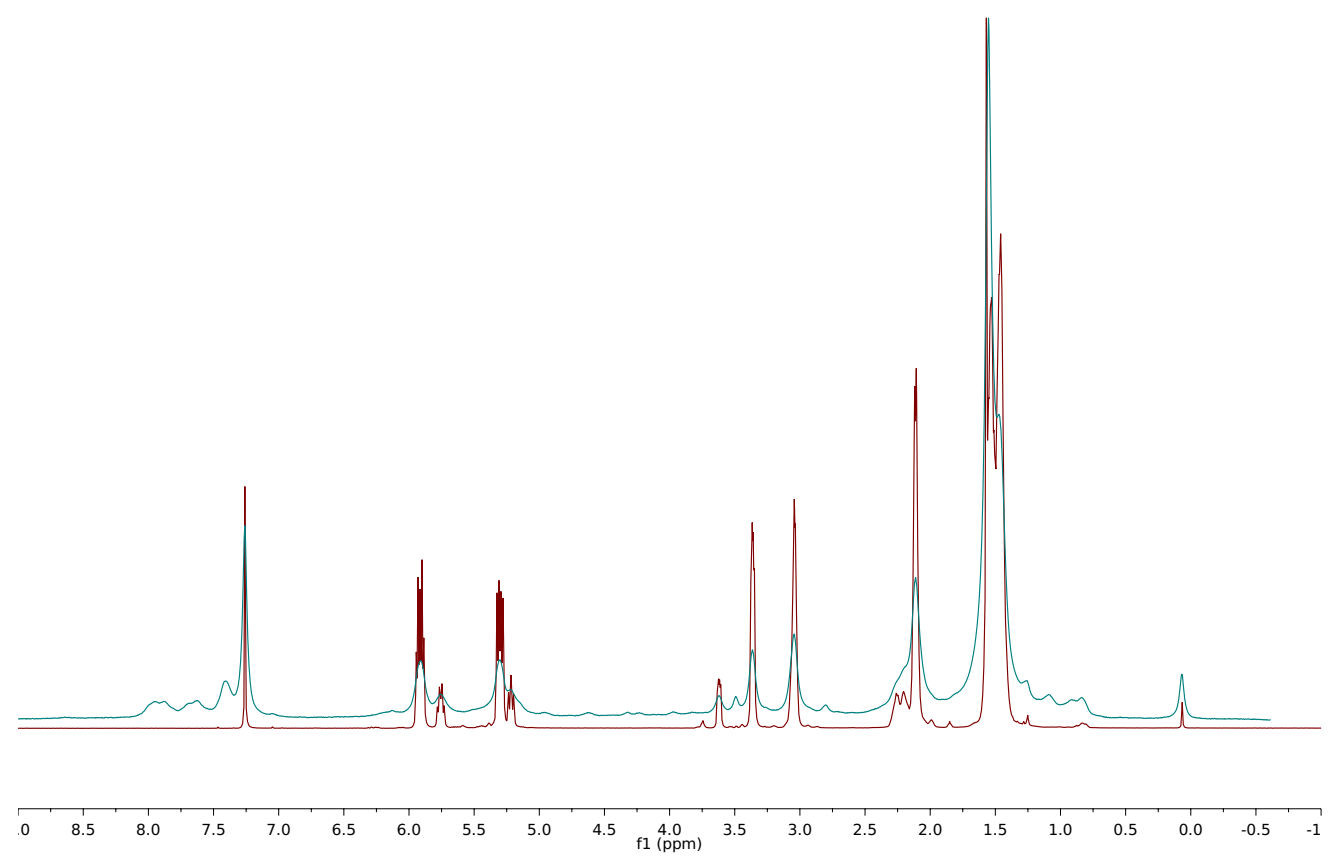

Figure S10: Overlay of ${ }^{1} \mathrm{H}$ NMR $\left(500 \mathrm{MHz}, \mathrm{CDCl}_{3}\right)$ before (red) and after (blue) sonication in the presence of 9-phenanthrol. 


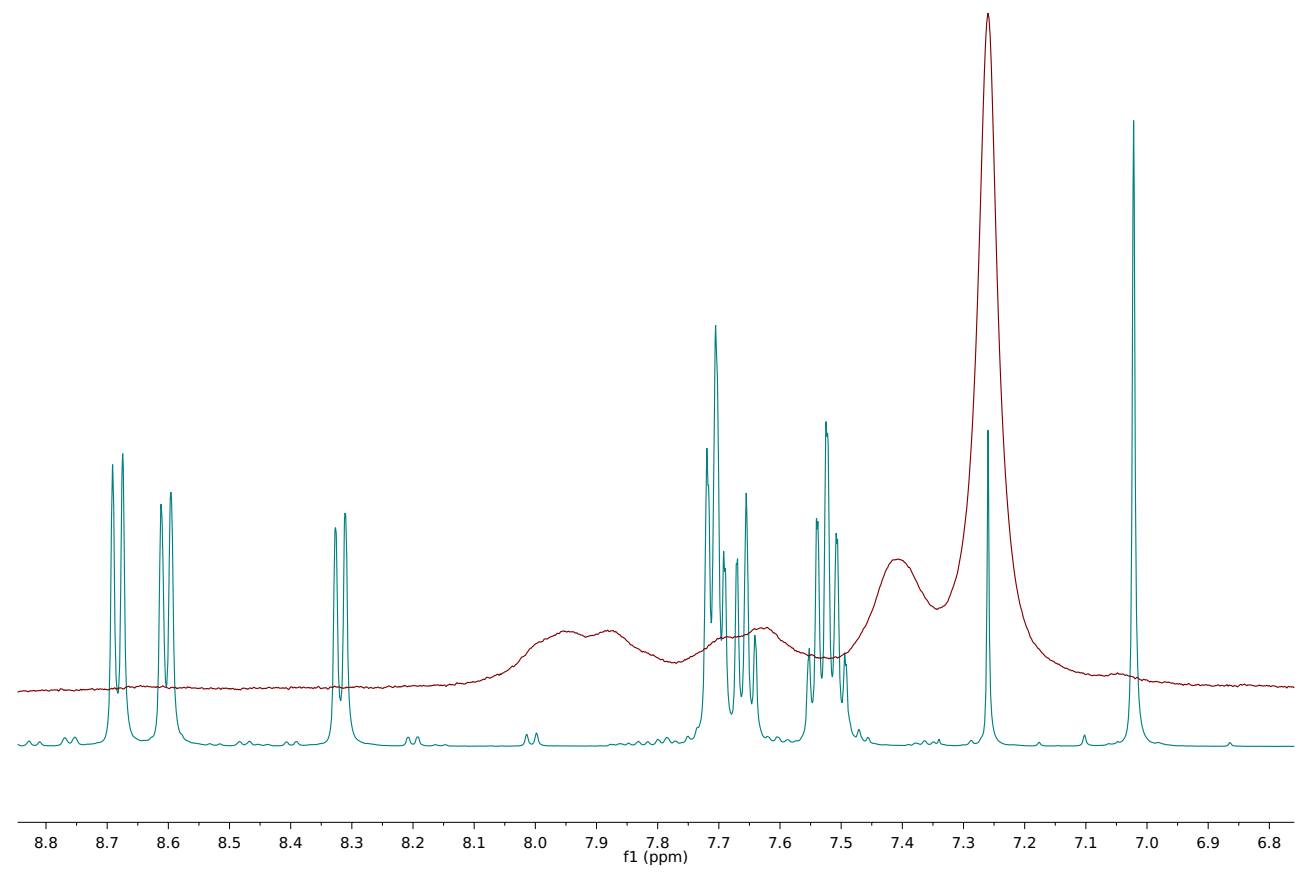

Figure S11: Overlay of ${ }^{1 \mathrm{H} \mathrm{NMR}}\left(500 \mathrm{MHz}, \mathrm{CDCl}_{3}\right)$ in the aromatic region after sonication (red) and the small molecule 9-phenanthrol, as purchased from Sigma-Aldrich (blue). 
A
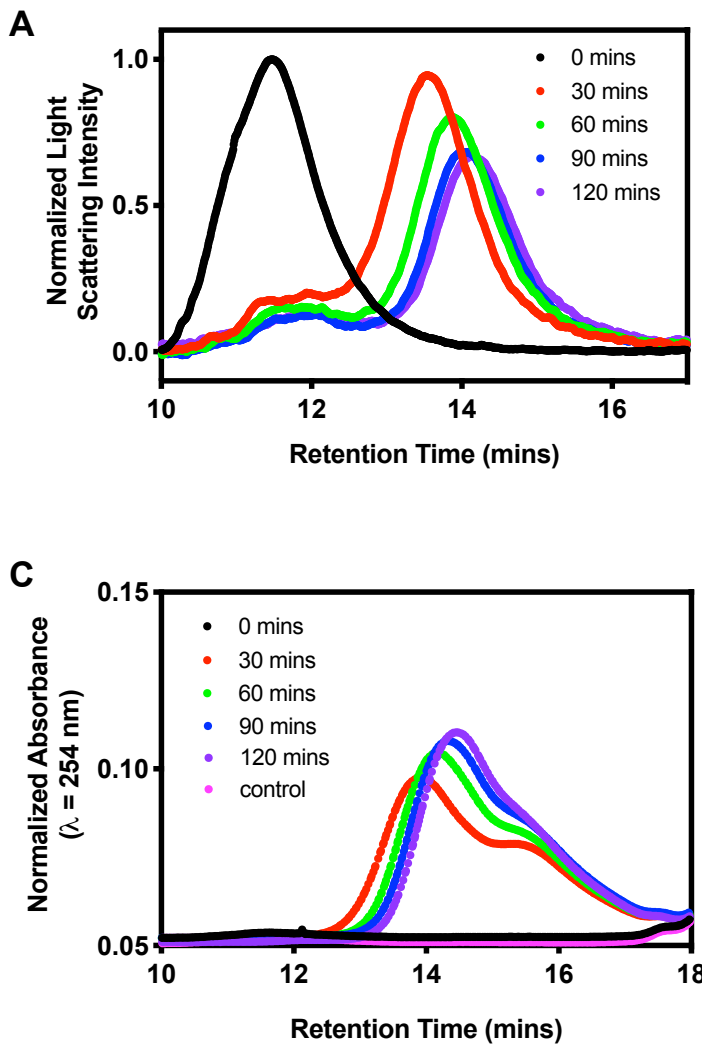
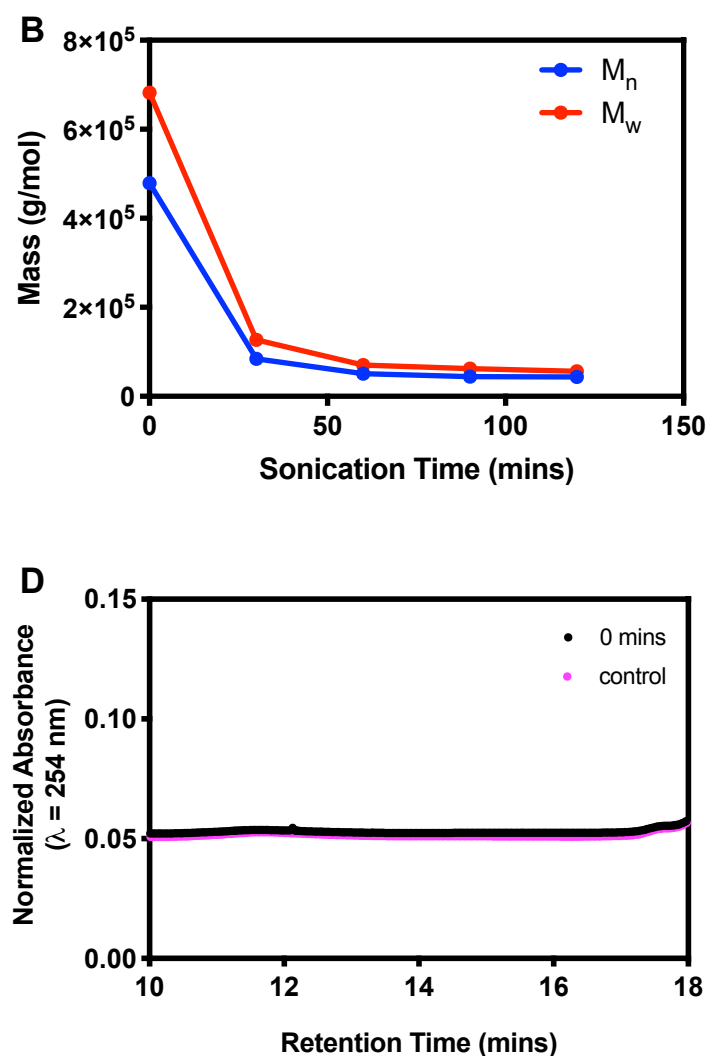

Figure S12: (A) The normalized light scattering signal for aliquots taken after different amounts of sonication time. (B) The number average and weighted average molar mass measured by determined by SEC-MALS over increased sonication time. (C) The UV-vis absorbance signal at $254 \mathrm{~nm}$ for aliquots taken at different sonication times. (D) The UV detector voltage at $254 \mathrm{~nm}$ for the polymer before sonication (black), and the same solution was characterized again by GPC after the sonication was completed, 4.5 hours later (pink). The maximum refractive index signal occurs at a retention time of 11.85 minutes.

\section{Room temperature control experiment}

The solution of polymer and 9-phenanthrol in THF was characterized by GPC prior to sonication experiment. The same solution, which had been sitting at room temperature during the sonication experiment, was characterized by GPC again immediately after the sonication experiment was completed. Absorbance at the retention time that the polymer was eluted was the same 4 hours later as it was when the solution was made (Figure S12). 


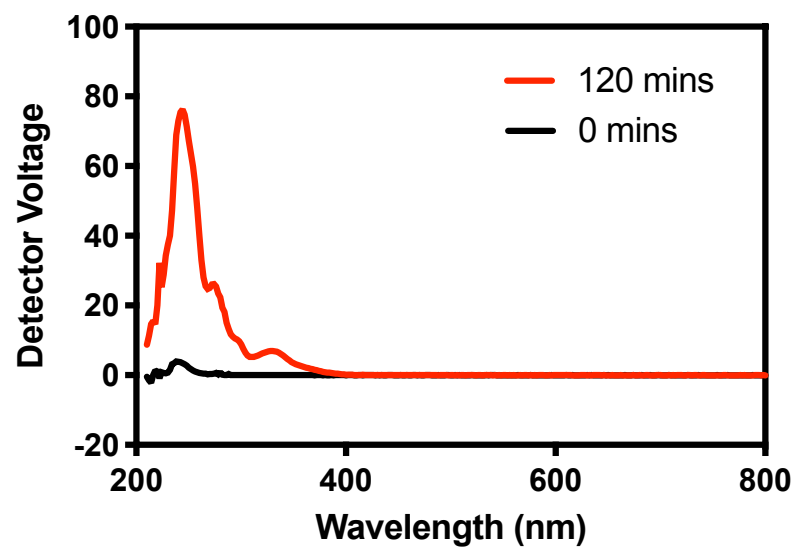

Figure S13: The UV-vis spectra collected at the retention time at the peak of the RI signal intensity for polymer $\mathbf{P} 1_{590}$ before (black) and after (red) sonication in a solution of 9-phenanthrol.

\section{Calculation of percent trapping by mass from UV-vis absorbance}

The percent trapping by 9-phenanthrol was determined according to the following Equation S3:

$$
w t \% \text { trapping }=\frac{\text { mass determined } \text { by } U V}{\text { mass determined by } R I} * 100
$$

To determine the mass by UV, the Astra software was configured to use the UV detector at $254 \mathrm{~nm}$ as the concentration source. The mass eluted over the entire UV peak was determined by the software based on the extinction coefficient of 9methoxyphenathrol. To determine the mass by $\mathrm{Rl}, 100 \%$ mass recovery of the polymer was assumed. The weight percent of 9 -phenanthrene is $9.1 \%$ and the molar percent of 9-methoxyphenanthrene is $5.9 \%$.

\section{Calculating percent trapping by "Protein Conjugate Analysis"}

The percent trapping by 9-phenanthrol was determined using the Astra software procedure "Protein Conjugate Analysis", which uses equations S4 and S5 to take into consideration the influence of trapping on the refractive index of the polymer in addition to the change in absorbance.

$$
\left(\frac{d n}{d c}\right)_{\text {conjugate }}=x_{\text {polymer }}\left(\frac{d n}{d c}\right)_{\text {polymer }}+\left(1-x_{\text {polymer }}\right)\left(\frac{d n}{d c}\right)_{9-\text { methoxyphenanthracene }}
$$

$$
\varepsilon_{\text {conjugate }}=\varepsilon_{\text {polymer }} * x_{\text {polymer }}+\varepsilon_{9-\text { methoxyphenanthracene }}\left(1-x_{\text {polymer }}\right)
$$


The extinction coefficient of the polymer at $254 \mathrm{~nm}\left(0 \mathrm{mg} \mathrm{mL}^{-1} \mathrm{~cm}^{-1}\right)$ and the $\mathrm{dn} / \mathrm{dc}$ of the polymer prior to sonication $\left(0.0859 \mathrm{~mL} \mathrm{~g}^{-1}\right)$ are entered into the software as the main component. The extinction coefficient $\left(221.0 \mathrm{mg} \mathrm{mL}^{-1} \mathrm{~cm}^{-1}\right)$ and $\mathrm{dn} / \mathrm{dc}$ of 9-methoxyphenanthrene $\left(0.2580 \mathrm{~mL} \mathrm{~g}^{-1}\right)$ are entered as the "modifier". The weight percent of 9-phenanthrene is $6.0 \%$, and the molar percent of 9-phenanthrene is $3.9 \%$.

\section{Determination of extinction coefficient of 9-methoxyphenanthcene}
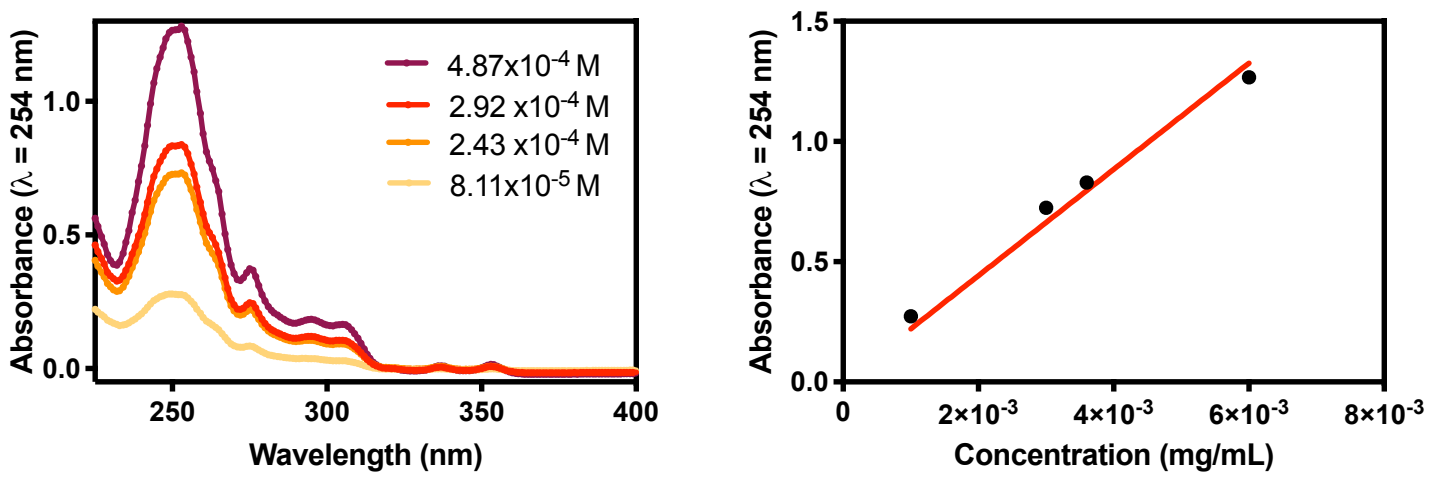

Figure S14: Left: Spectra of various concentrations of 9-methoxyphenanthcene in THF. Right: Beer's law plot at $254 \mathrm{~nm}$, the wavelength that is used for GPC calculations. The $R^{2}$ value is 0.9778 and the calculated molar absorptivity is $221.0 \mathrm{mg} \mathrm{mL}^{-1} \mathrm{~cm}^{-1}$.

\section{Determination of refractive index increment of 9-methoxyphenanthrene}

The following concentrations of 9-phenanthrol were prepared in HPLC-grade THF by weight (not as a serial dilution): $0.150 \mathrm{mg} / \mathrm{mL}, 0.285 \mathrm{mg} / \mathrm{mL}, 0.412 \mathrm{mg} / \mathrm{mL}$, $0.656 \mathrm{mg} / \mathrm{mL}, 0.829 \mathrm{mg} / \mathrm{mL}$, and $1.055 \mathrm{mg} / \mathrm{mL}$. The THF solvent was passed through the Wyatt Optilab T-rEX RI detector with a syringe pump at a flow rate of $0.3 \mathrm{~mL} / \mathrm{min}$, followed by each of the concentrations. Each solution was pumped through until several minutes of data were collected. After the highest concentration was ran, the THF solvent was ran again to set a baseline. The Astra procedure "dn/dc from Rl" was applied to the data to calculate $\mathrm{dn} / \mathrm{dc}=0.2580 \pm$ $0.0047 \mathrm{~mL} / \mathrm{g}, \mathrm{r}^{2}=0.9987$. 

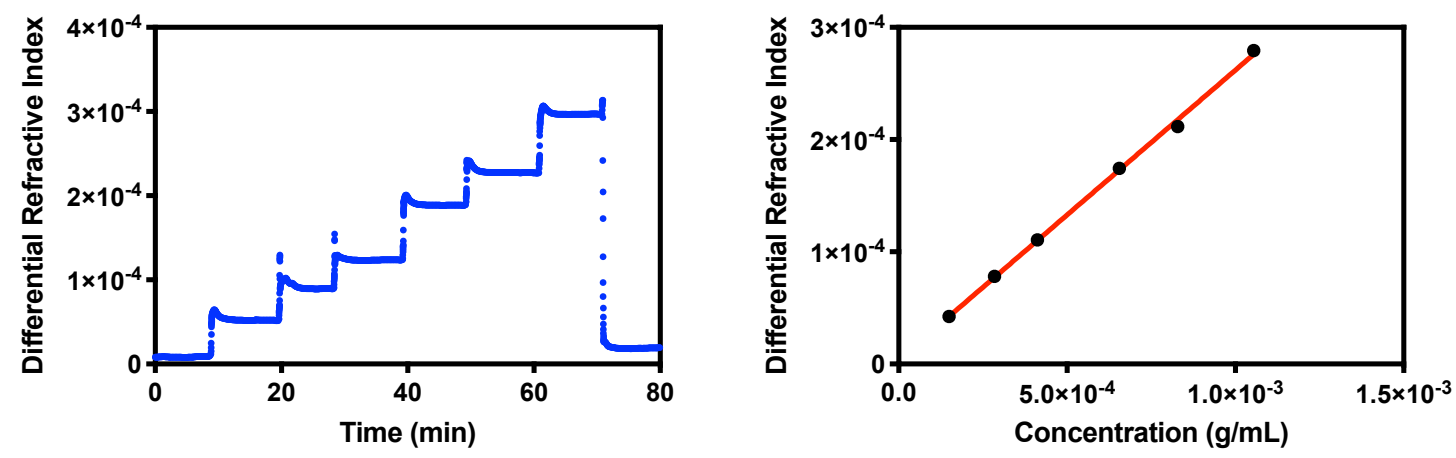

Figure S15: Left: The refractive index measured over the time of the experiment, where each plateau corresponds to a different concentration of 9-methoxyphenanthrol flowing through the detector. Right: The slope of the linear regression of the refractive index measured for each concentration gives the refractive index increment. 


\section{Mechanochemically Induced Cross-Linking}

We observed that when 9-phenanthrol was present, the PDI of P1590 decreased during sonication. When the same polymer was sonicated without 9-phenanthrol, the PDI increased. Typically, PDI decreases with sonication time as larger polymers are broken in half. In previous work, the observation of PDI increasing with sonication time indicated cross-linking. ${ }^{5}$

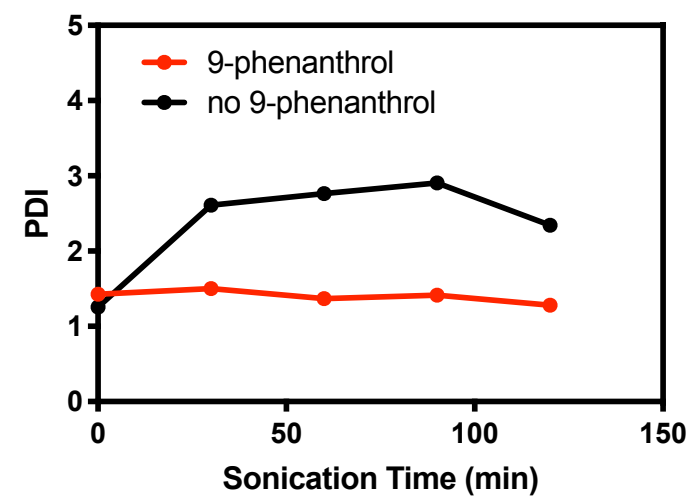

Figure S16: The change in PDI during sonication of same polymer with (red) and without (black) 9-phenanthrol.

Sonication of $P 1_{420}$ above the overlap concentration

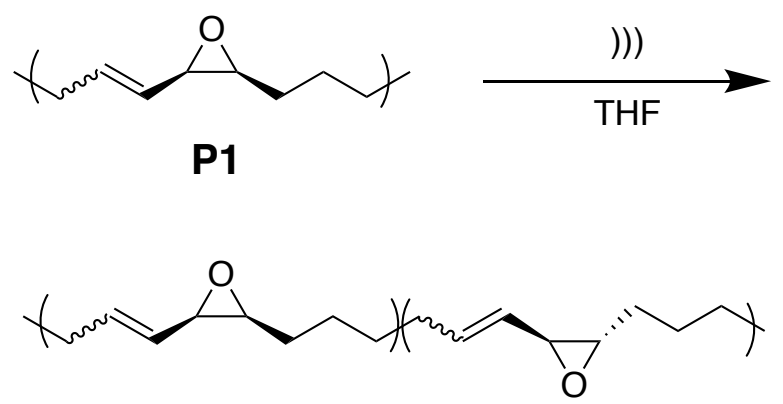

In order to investigate whether the polymer could crosslink with itself, polymer $P 1_{420}$ was sonicated at a concentration of $16.8 \mathrm{mg} / \mathrm{mL}$, above $\mathrm{c}^{*}=5.8 \mathrm{mg} / \mathrm{mL}$. 

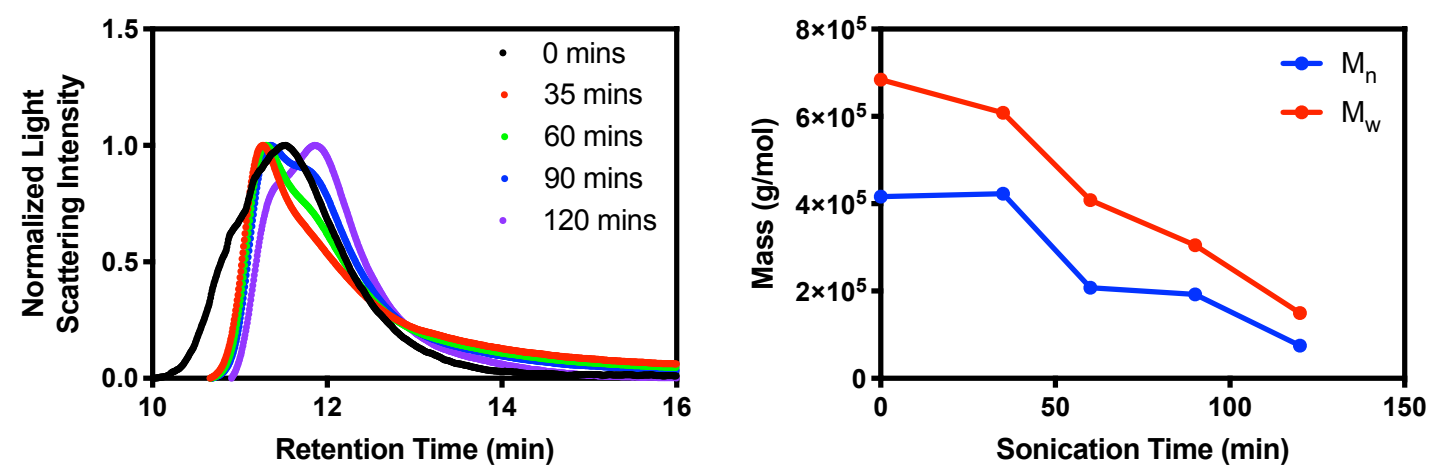

Figure S17: $M_{n}$ and $M_{w}$ both decrease with increased sonication time, but the retention time at max peak height for the light scattering trace increases from the original polymer to sonication time of 90 minutes.

The calculated molecular weight of the polymer did not increase. However, the light scattering intensity reaches its maximum at a shorter retention time after the polymer is sonicated. It appears that some cross-linking can occur between the homopolymer itself.

\section{Determining the monomer composition of $\mathbf{P 2} 190$}

Fraction monomer $\mathbf{2}=\frac{\left(\frac{\left.{ }_{\text {monomer } 2 \text { vinyl }}\right)}{2}\right)}{\frac{H_{\text {monomer } 2 \text { vinyl }}}{2}+H_{\text {epoxyCOD vinyl }}}=0.51$

$\mathrm{H}_{\text {vinyl monomer 2 }}=\int 5.549-5.343=2.36$

$\mathrm{H}_{\text {vinyl epoxy COD }}=\int 5.338-5.186=1.15$ 


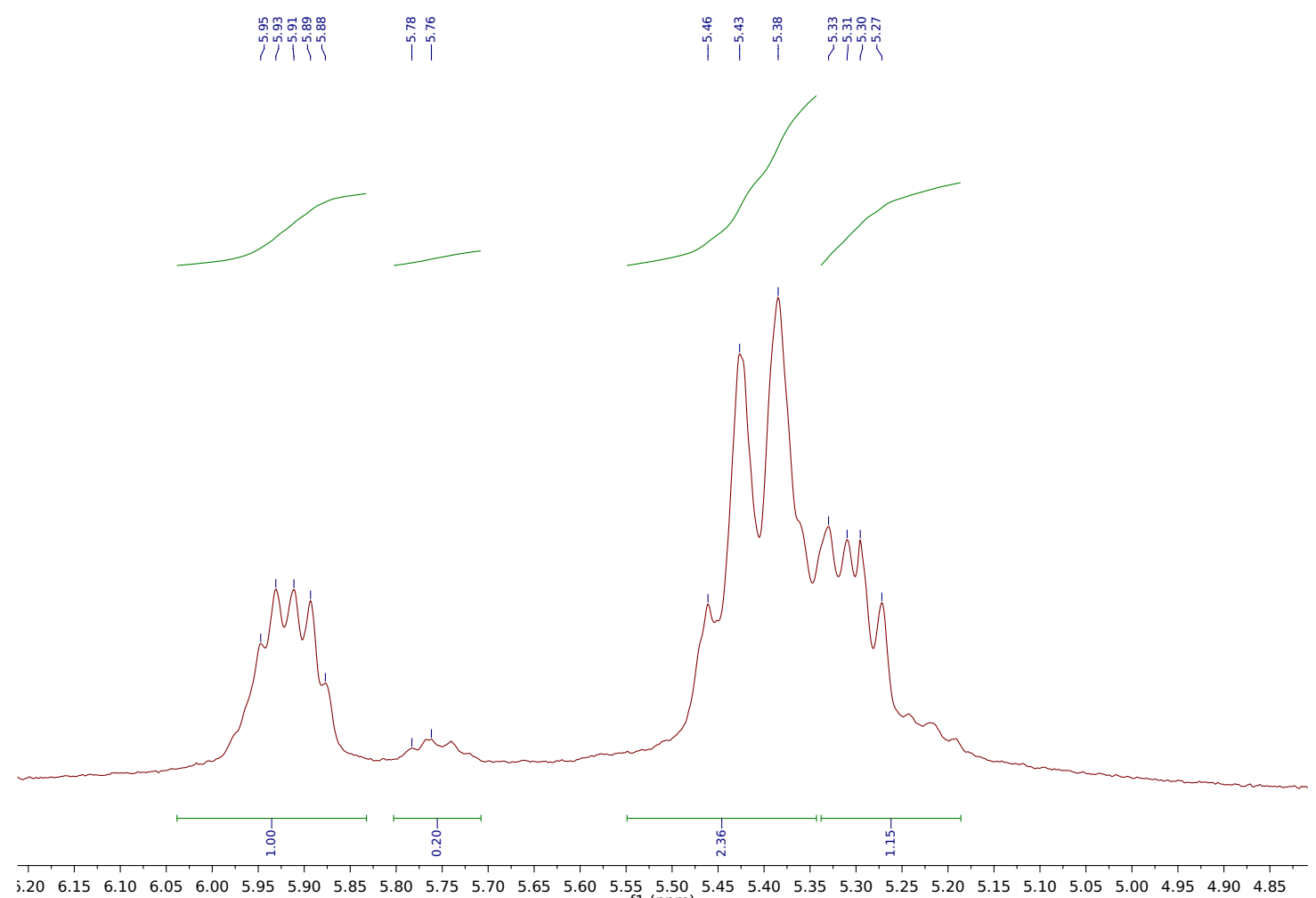

$\begin{array}{llllllllllllllllllllllllllllllllllllllll}j .20 & 6.15 & 6.10 & 6.05 & 6.00 & 5.95 & 5.90 & 5.85 & 5.80 & 5.75 & 5.70 & 5.65 & 5.60 & 5.55 & 5.50 & 5.45 & 5.40 & 5.35 & 5.30 & 5.25 & 5.20 & 5.15 & 5.10 & 5.05 & 5.00 & 4.95 & 4.90 & 4.85\end{array}$

Figure S18: ${ }^{1} \mathrm{H}$ NMR (400 MHz, $\mathrm{CDCl}_{3}$ ) of $\mathbf{P} \mathbf{2}_{190}$ prior to sonication showing the region integrated to determine the monomer content.

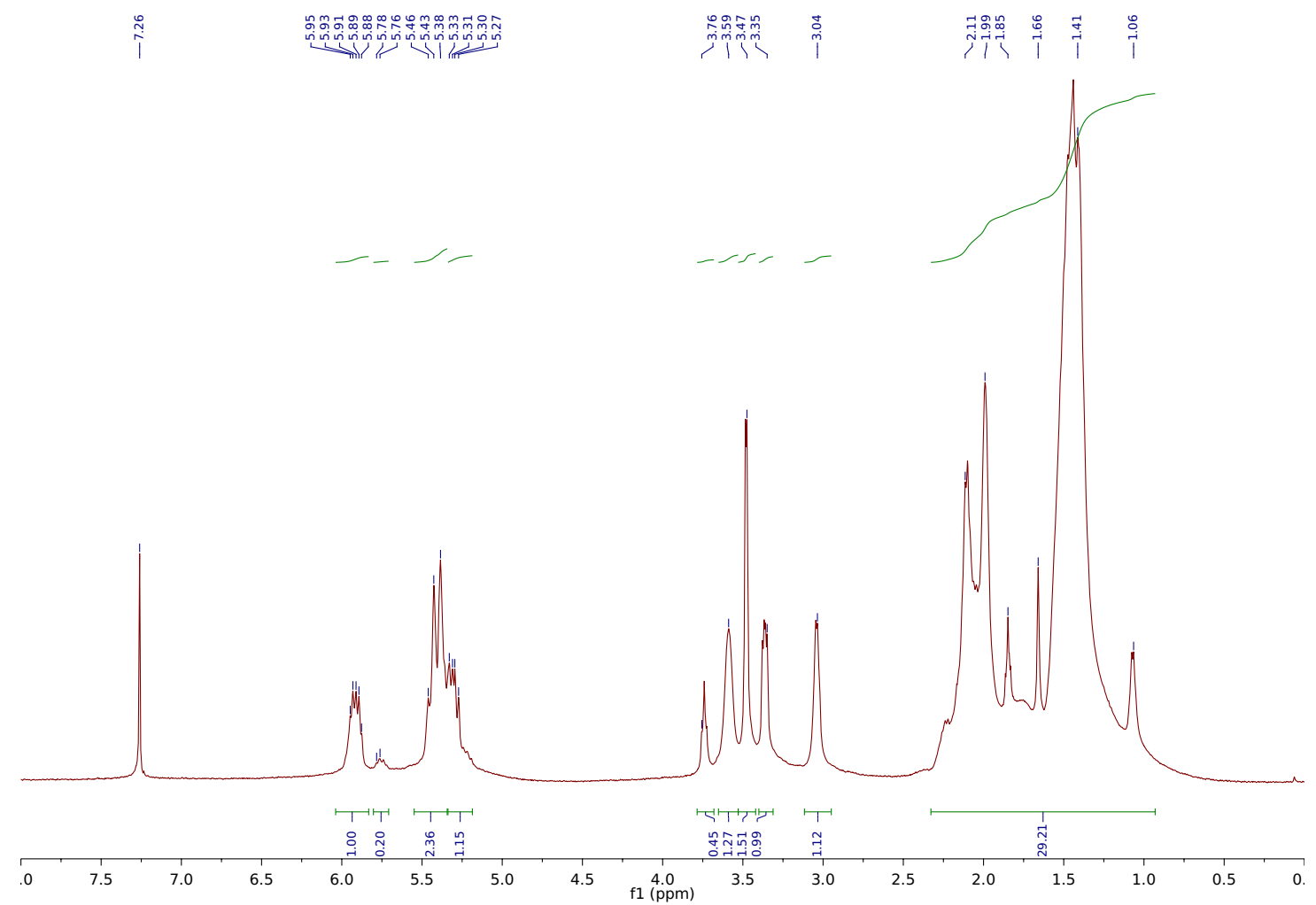

Figure S19: ${ }^{1} \mathrm{H}$ NMR (400 MHz, $\mathrm{CDCl}_{3}$ ) of $\mathbf{P} \mathbf{2}_{190}$ prior to sonication. 

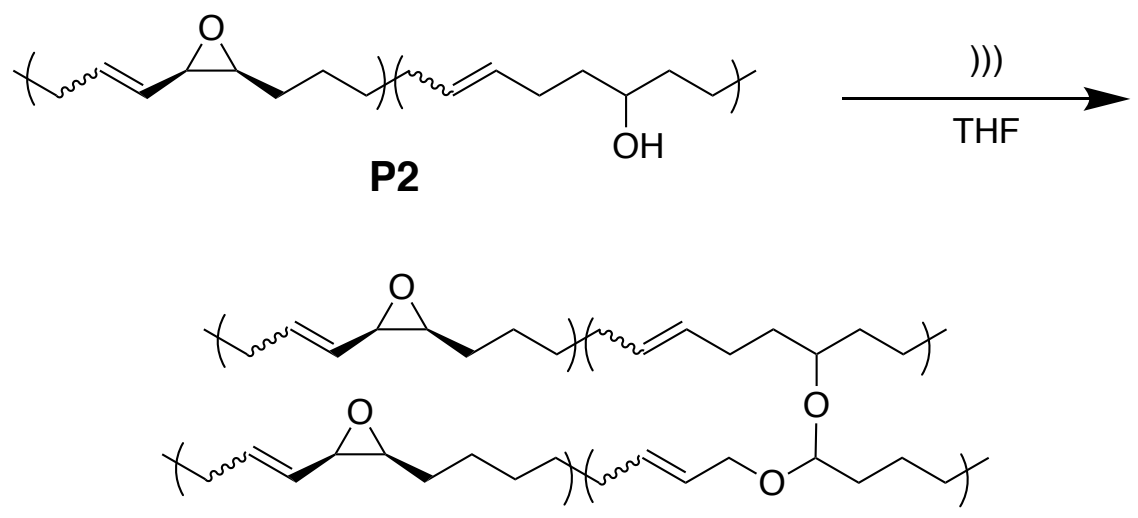

\section{Sonication of $\mathbf{P 2} 190$ at low concentration $(1 \mathrm{mg} / \mathrm{mL})$}
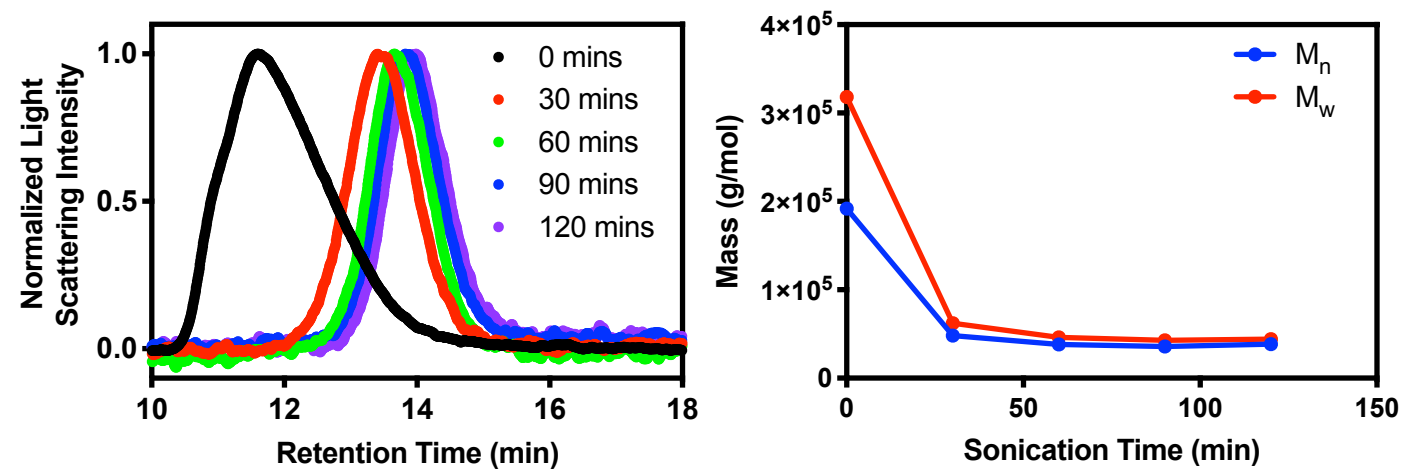

Figure S20: Molecular weight degradation during sonication at $1.0 \mathrm{mg} / \mathrm{mL}$ of polymer $\mathbf{P} \mathbf{2}_{230}$ in THF (left) and light scattering signals from SEC-MALS for aliquots taken at different sonication times (right).

Sonication of $\mathbf{P} \mathbf{2}_{230}$ at intermediate concentration $(10 \mathrm{mg} / \mathrm{mL})$
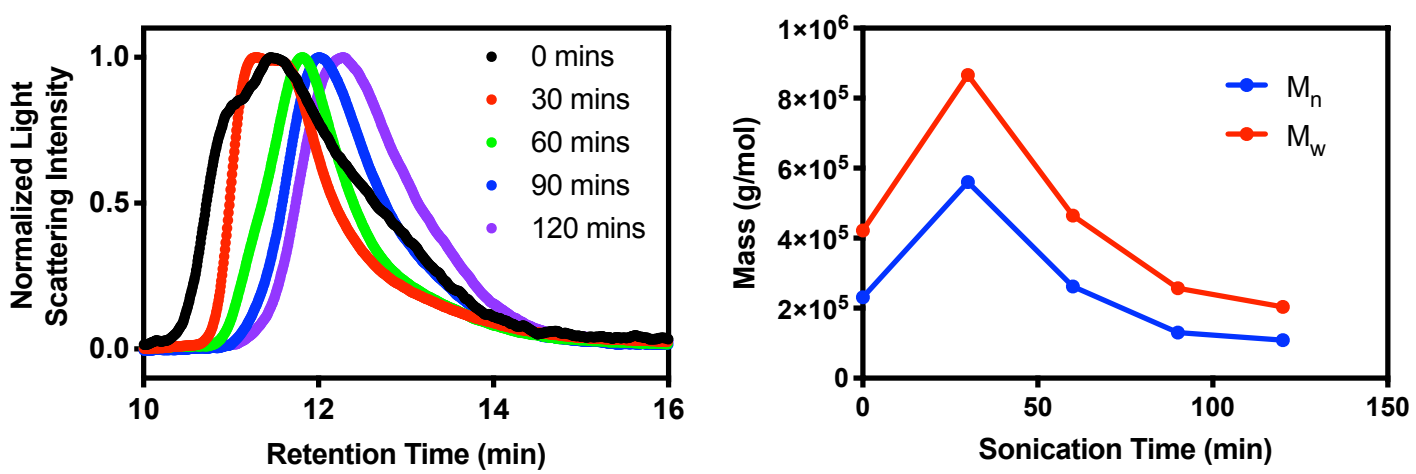

Figure S21: Light scattering signals from SEC-MALS for aliquots taken at different sonication times (right) and molecular weight degradation (left) during sonication at $10 \mathrm{mg} / \mathrm{mL}$ of polymer $\mathbf{P} \mathbf{2}_{\mathbf{2 3 0}}$ in THF. 
Sonication of $\mathbf{P} \mathbf{2}_{230}$ at high concentration $(20 \mathrm{mg} / \mathrm{mL})$
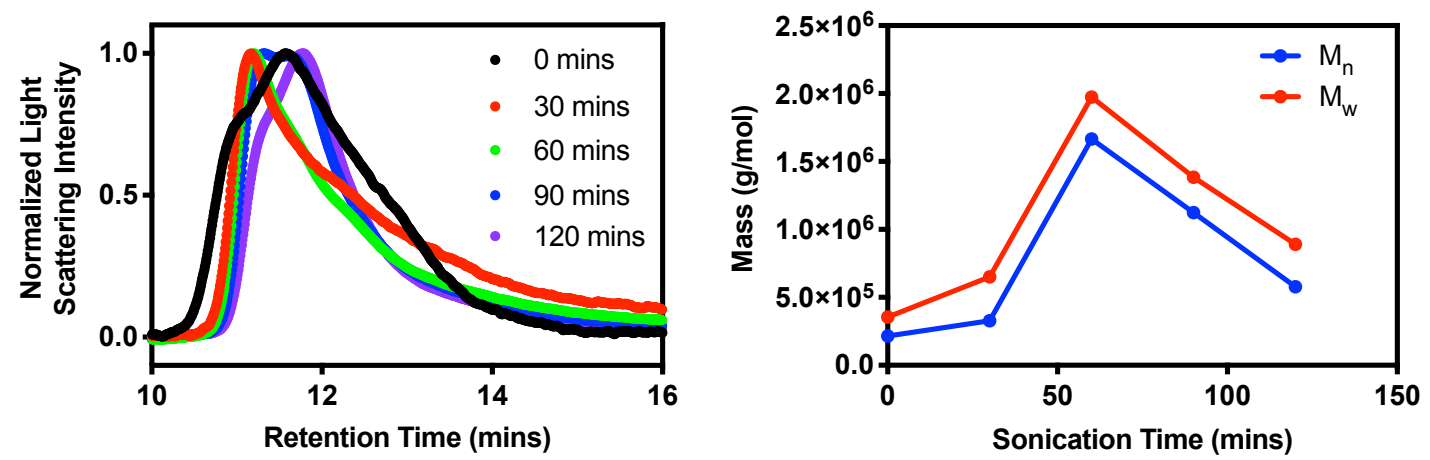

Figure S22: Light scattering signals from SEC-MALS for aliquots taken at different sonication times (right) and molecular weight degradation (left) during sonication at $20 \mathrm{mg} / \mathrm{mL}$ of polymer $\mathbf{P} \mathbf{2}_{\mathbf{2 3 0}}$ in THF.
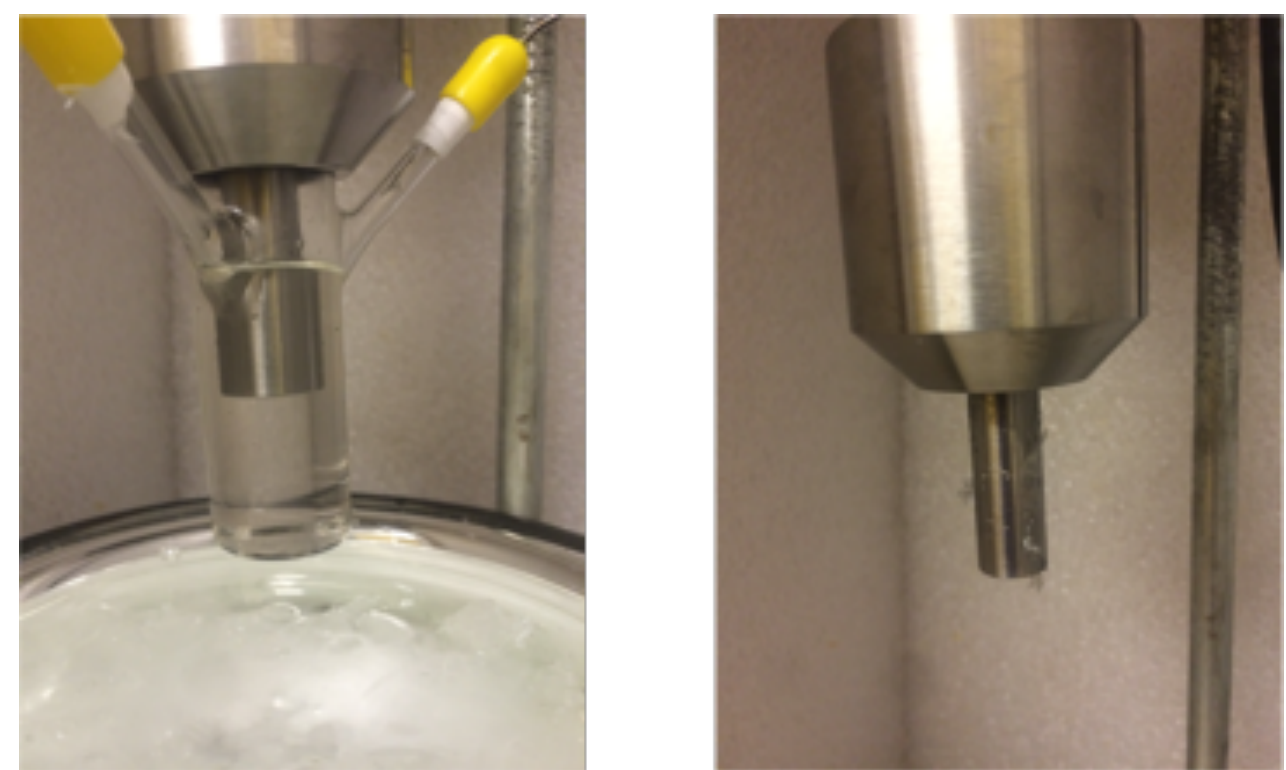

Figure S23: Only slight gelation occurred, and it was not apparent until the sonication tip was cleaned. Photos taken with an iPhone 5s and unedited. 


\section{Control Experiments}

\section{Trapping and isomerization require mechanical force}

\section{Sonication of $\mathbf{P} \mathbf{1}_{8}$}

Polymer P18 was dissolved in $0.1 \mathrm{M}$ 9-phenanthrol at $1.5 \mathrm{mg} / \mathrm{mL}$ and sonicated under standard conditions for 120 minutes. After sonication, the solution was concentrated and precipitated 2 times into cold methanol to collect the sonicated polymer for ${ }^{1} \mathrm{H}$ NMR. The absorbance at $254 \mathrm{~nm}$ is shown in Figure 2D.
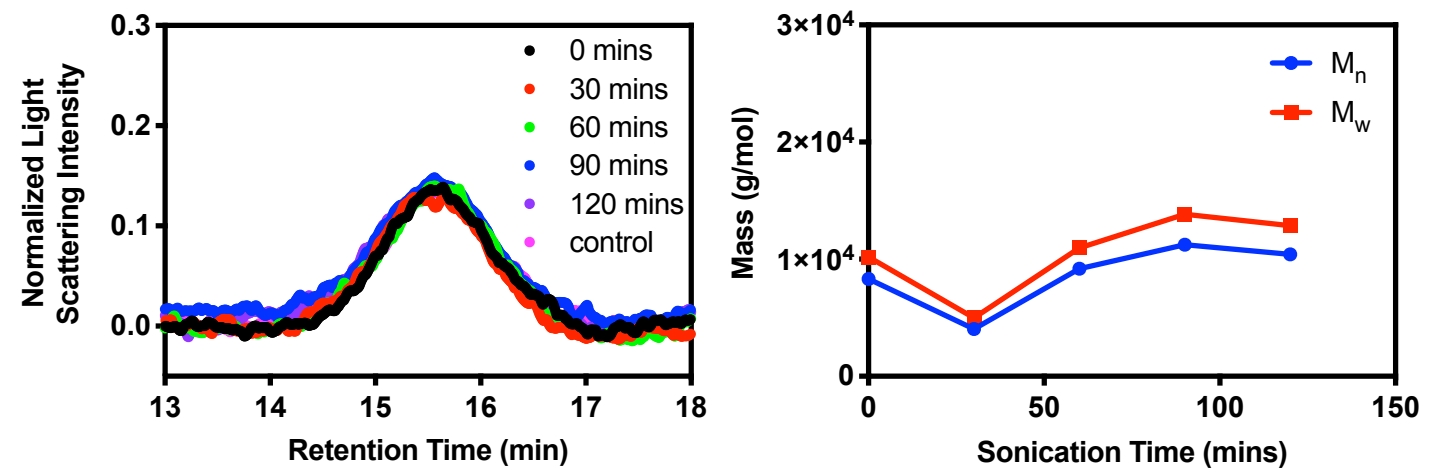

Figure S24: Normalized light scattering intensity (left) and number average and weighted average molar mass (right) for aliquots taken out at different sonication times. The control solution was left under ambient conditions for the duration of the experiment ( 4.5 hours) before running on GPC. 


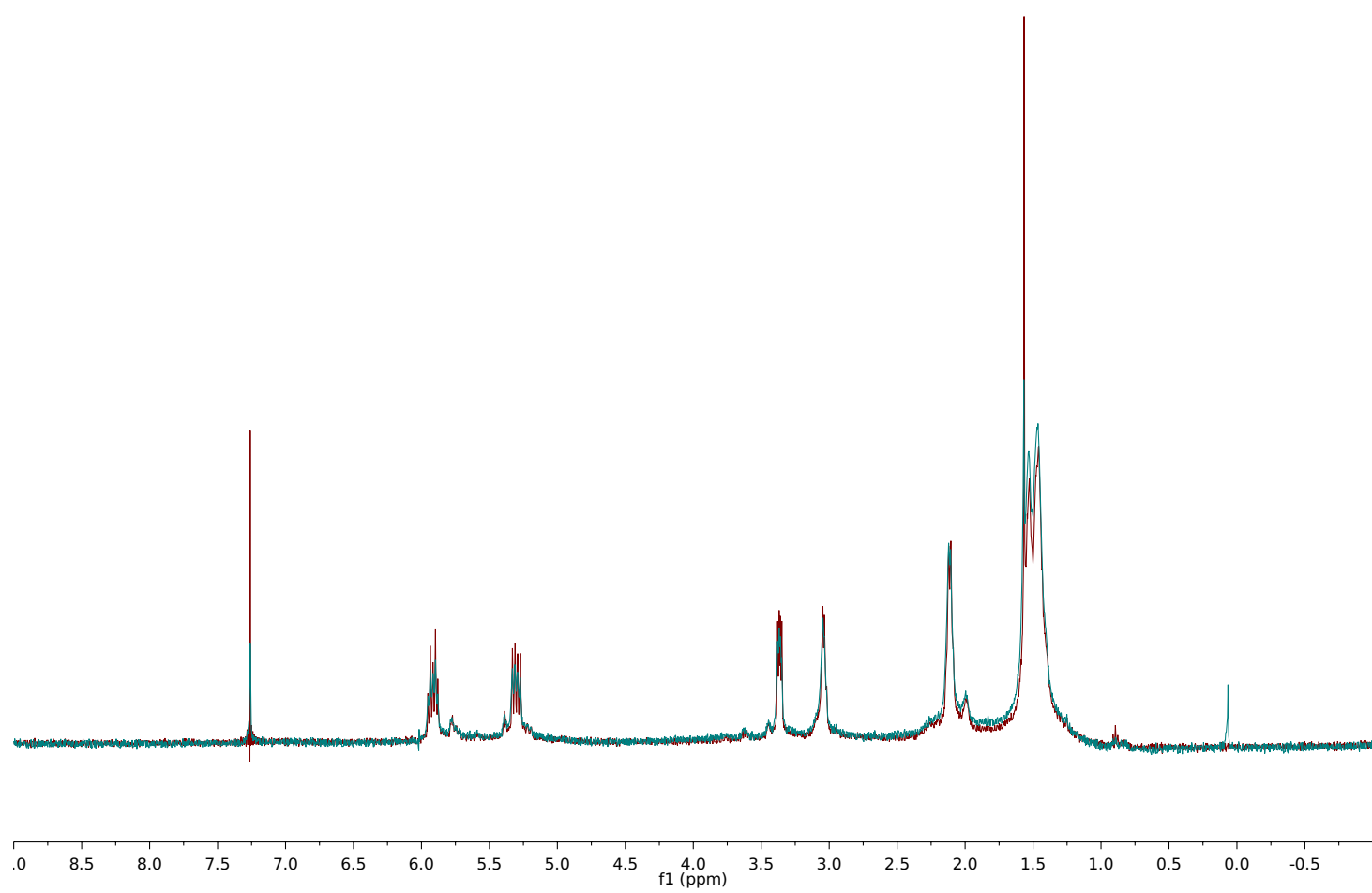

Figure S25: ${ }^{1} \mathrm{H}$ NMR (500 MHz, $\mathrm{CDCl}_{3}$ ) of Polymer $\mathbf{P} \mathbf{1}_{\mathbf{8}}$ before sonication (red) and after (blue) sonication in a $0.1 \mathrm{M}$ solution of 9-phenanthrol in THF. Following sonication, the polymer solution is concentrated then precipitated twice in cold methanol prior to taking the ${ }^{1 \mathrm{H}}$ NMR.

\section{Cross-linking requires mechanical force}

Sonication of $\mathbf{P} \mathbf{1}_{20}$ above the overlap concentration

Polymer $\mathbf{P} 1_{20}$ was dissolved in THF at $35.1 \mathrm{mg} / \mathrm{mL}$, above $\mathrm{c}^{*}=16.8 \mathrm{mg} / \mathrm{mL}$ (see section on calculation of the overlap concentration), then sonicated for 120 minutes. Aliquots were taken for GPC and after sonication the solvent was removed by rotary evaporation for ${ }^{1} \mathrm{H}$ NMR. 

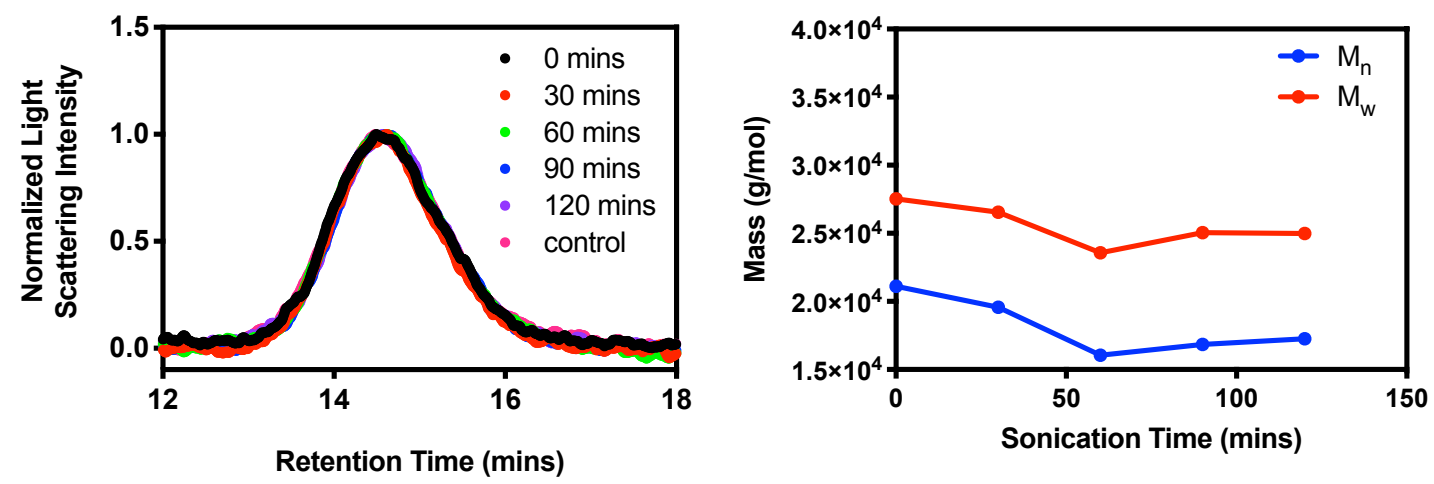

Figure S26: Normalized light scattering intensity (left) and number average and weighted average molar mass (right) for aliquots taken out at different sonication times. The control solution was left under ambient conditions for the duration of the experiment ( 4.5 hours) before running on GPC.

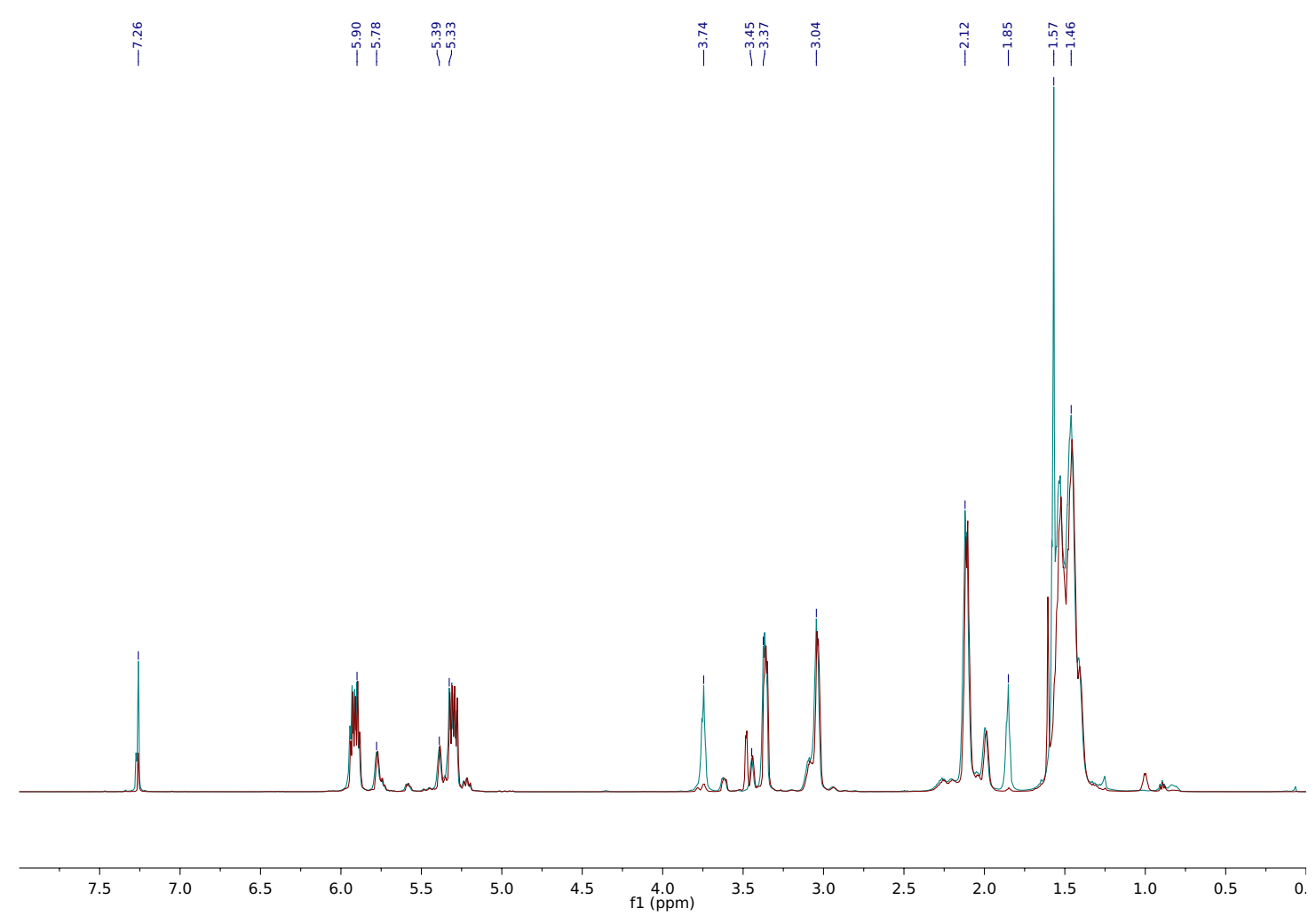

Figure S27: ${ }^{1} \mathrm{H}$ NMR (500 MHz, $\mathrm{CDCl}_{3}$ ) of $\mathbf{P 1}_{20}$ before (red) and after (blue) sonication above the overlap concentration at $35.1 \mathrm{mg} / \mathrm{mL}$. The new peaks at 1.85 and 3.74 in the blue spectra are THF, the solvent for the sonication experiment. 


\section{Sonication of $\mathbf{P} \mathbf{2}_{30}$ above the overlap concentration}

Polymer P2 30 was dissolved in THF at a concentration of $32.7 \mathrm{mg} / \mathrm{mL}$, above $\mathrm{c}^{\star}=$ $16.9 \mathrm{mg} / \mathrm{mL}$ (see section on calculation of the overlap concentration, and sonicated for 120 minutes. Aliquots were taken for GPC and after sonication the solvent was removed by rotary evaporation for ${ }^{1} \mathrm{H}$ NMR.
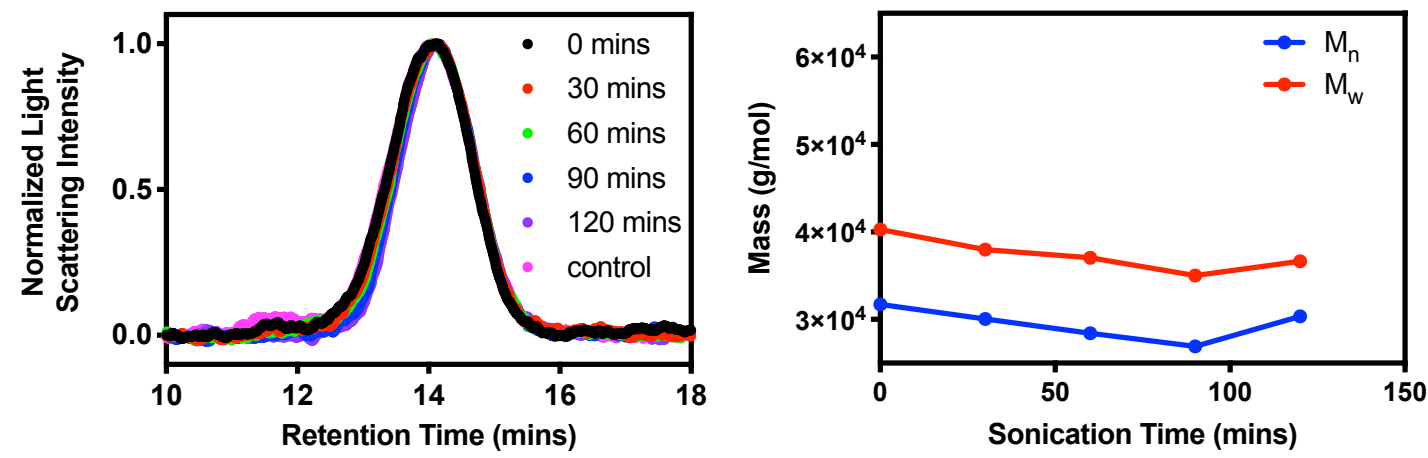

Figure S28: Normalized light scattering intensity (left) and number average and weighted average molar mass (right) for aliquots taken out at different sonication times. The control solution was left under ambient conditions for the duration of the experiment ( 4.5 hours) before GPC characterization.

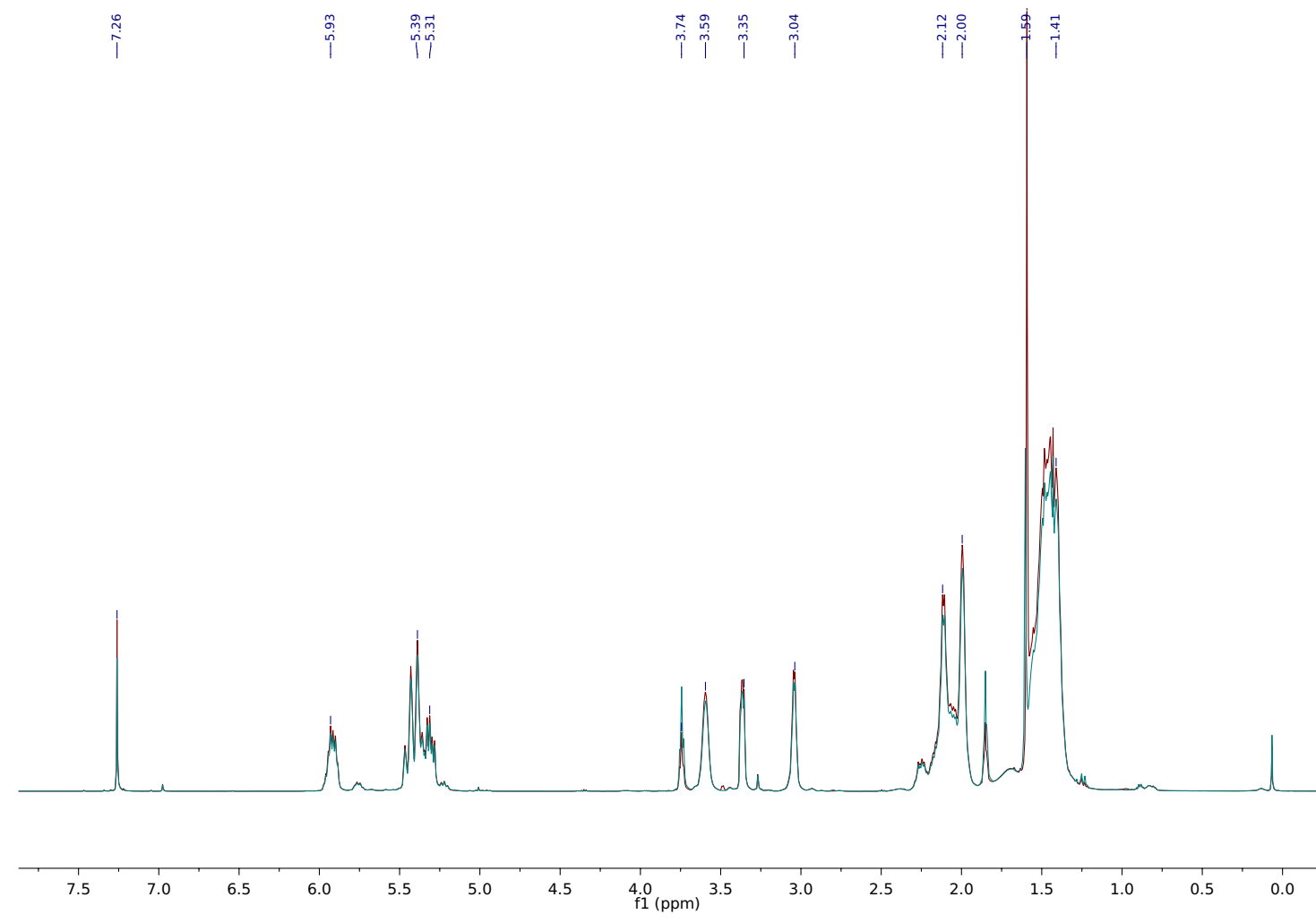

Figure S29: ${ }^{1} \mathrm{H}$ NMR $\left(500 \mathrm{MHz}, \mathrm{CDCl}_{3}\right.$ ) of $\mathbf{P} \mathbf{2}_{30}$ before (red) and after (blue) sonication above the overlap concentration at $35.1 \mathrm{mg} / \mathrm{mL}$. 


\section{Determining the monomer composition of $\mathbf{P} \mathbf{2}_{\mathbf{3}}$}

Fraction monomer $\mathbf{2}=\frac{\left(\frac{{ }_{\text {monomer } 2 \text { vinyl }}}{2}\right)}{\frac{H_{\text {monomer } 2 \text { vinyl }}}{2}+H_{\text {epoxyCOD vinyl }}}=0.54$

$\mathrm{H}_{\text {vinyl monomer 2 }}=\int 5.549-5.343=1.77$

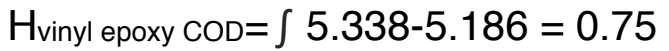

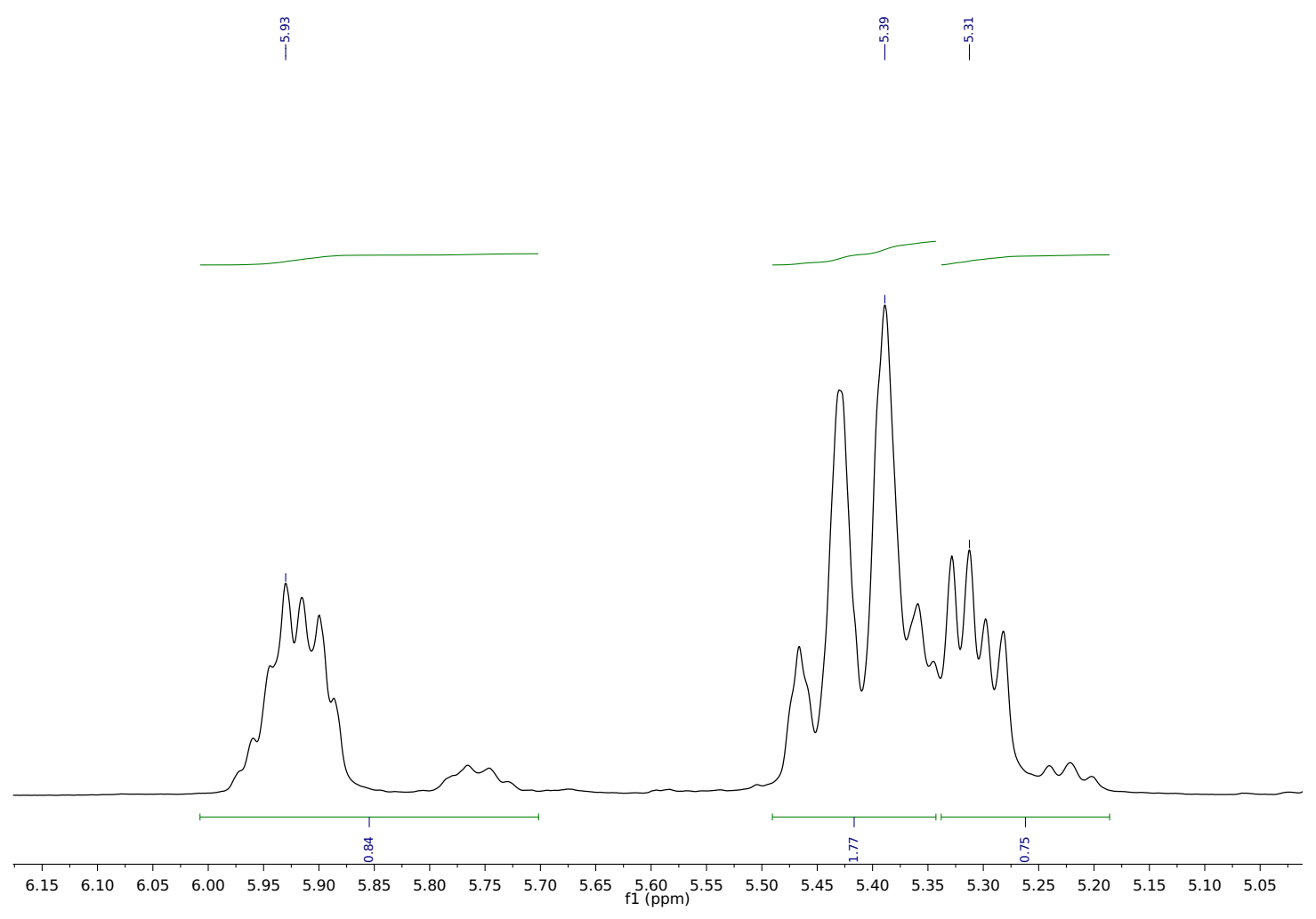

Figure S30: ${ }^{1} \mathrm{H}$ NMR (500 MHz, $\mathrm{CDCl}_{3}$ ) of $\mathbf{P} \mathbf{2}_{30}$ prior to sonication showing the regions integrated to determine the monomer content. 


\section{Overlap Concentration $\left(c^{\star}\right)$ Calculations}

The overlap concentration occurs when the volume of a polymer is equivalent to the volume of the system and polymers are in contact with each other. It was calculated according to a previously published method. ${ }^{6}$ Overlap concentrations are shown in Table S3.

Table S3: Overlap concentrations for polymers used in cross-linking experiments.

\begin{tabular}{|c|c|c|c|c|c|}
\hline Polymer & $\mathrm{Mn}_{\mathrm{n}}(\mathrm{kDa})$ & $M_{w}(k D a)$ & PDI & $R_{g}(n m)$ & $\begin{array}{l}\mathrm{C}^{*} \\
(\mathrm{mg} / \mathrm{mL})\end{array}$ \\
\hline$P 1_{420}$ & 416 & 684 & 1.64 & 36.0 & 5.8 \\
\hline $\mathbf{P} 1_{20}$ & 21 & 28 & 1.30 & $8.66^{*}$ & 16.8 \\
\hline P2190 & 192 & 318 & 1.66 & 32.8 & 3.6 \\
\hline P2230 & 231 & 442 & 1.82 & 36.7 & 3.5 \\
\hline P230 & 32 & 40 & 1.27 & $9.4^{*}$ & 16.9 \\
\hline
\end{tabular}

${ }^{*}$ calculated by linear regression of $\mathrm{Rg}$ vs. $\mathrm{M}^{1 / 2}$ for a larger polymer of the same composition.

Determining the overlap concentration of $\boldsymbol{P 1}_{420}$

$M_{n}=416,200, M_{w}=684,200, R_{g}=36.0 \mathrm{~nm}$

$$
\begin{gathered}
\text { Volume of a polymer }=\frac{4}{3} \pi R_{g}^{3} \\
\text { Volume of a polymer }=\frac{4}{3} \pi\left(3.60 \cdot 10^{-6} \mathrm{~cm}\right)^{3}=1.95 \cdot 10^{-16} \mathrm{~cm}^{3} \\
\frac{1 \mathrm{polymer}}{1.95 \cdot 10^{-16} \mathrm{~cm}^{3}} \cdot \frac{1 \mathrm{~mol}}{6.022 \cdot 10^{23} \text { polymers }} \cdot \frac{442,300 \mathrm{~g}}{\mathrm{~mol}}=0.0058 \frac{\mathrm{g}}{\mathrm{cm}^{3}}=5.8 \frac{\mathrm{mg}}{\mathrm{mL}}
\end{gathered}
$$

Determining the overlap concentration of $\mathbf{P 1}_{20}$

Since the molecular weight of polymer $\mathbf{P} \mathbf{1}_{20}$ is low, the radius is less than $10 \mathrm{~nm}$ and cannot be determined from SEC-MALS using a Debye plot. In order to determine radius of $\mathbf{P} \mathbf{1}_{20}$, the relationship between $R_{g}$ and mass is determined for a larger polymer, $\mathbf{P} \mathbf{1}_{420}$. The mass and radius are recorded at several retention times across the light scattering peak for a GPC chromatogram of P1420. The radius should scale linearly with the square root of mass for a random coil polymer, as shown in Figure S31. The calculated $R_{g}$ is determined from the linear regression constrained to the origin. 


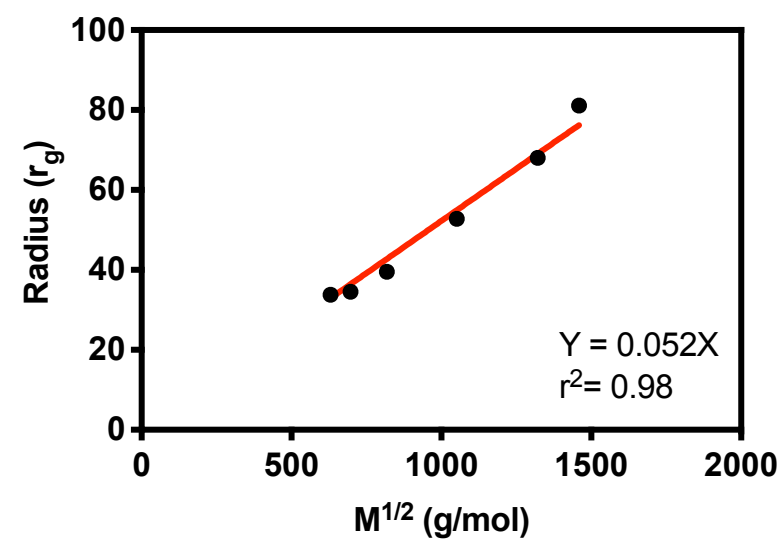

Figure S31: The radius of gyration plotted as a function of the square root of the molar mass.

For $\mathbf{P 1 2 0}, M_{n}=21,000, M_{w}=27,500$, and the calculated value of $R_{g}=8.66$.

$$
\begin{gathered}
\text { Volume of a polymer }=\frac{4}{3} \pi R_{\mathrm{g}}^{3} \\
\text { Volume of a polymer }=\frac{4}{3} \pi\left(8.66 \cdot 10^{-7} \mathrm{~cm}\right)^{3}=2.72 \cdot 10^{-18} \mathrm{~cm}^{3} \\
\frac{1 \mathrm{polymer}}{2.72 \cdot 10^{-18} \mathrm{~cm}^{3}} \cdot \frac{1 \mathrm{~mol}}{6.022 \cdot 10^{23} \text { polymers }} \cdot \frac{27,500 \mathrm{~g}}{\mathrm{~mol}}=0.0168 \frac{\mathrm{g}}{\mathrm{cm}^{3}}=16.8 \frac{\mathrm{mg}}{\mathrm{mL}}
\end{gathered}
$$

Determining the overlap concentration for $\mathbf{P} \mathbf{2}_{190}$

$M_{n}=191,700, M_{w}=318,000$ and $R_{g}=32.8 \mathrm{~nm}$, and $c^{*}=3.5 \mathrm{mg} / \mathrm{mL}$

$$
\begin{gathered}
\text { Volume of a polymer }=\frac{4}{3} \pi R_{g}^{3} \\
\text { Volume of a polymer }=\frac{4}{3} \pi\left(3.28 \cdot 10^{-6} \mathrm{~cm}\right)^{3}=1.48 \cdot 10^{-16} \mathrm{~cm}^{3} \\
\frac{1 \text { polymer }}{1.48 \cdot 10^{-16} \mathrm{~cm}^{3}} \cdot \frac{1 \mathrm{~mol}}{6.022 \cdot 10^{23} \text { polymers }} \cdot \frac{318,000 \mathrm{~g}}{\mathrm{~mol}}=0.0036 \frac{\mathrm{g}}{\mathrm{cm}^{3}}=3.6 \frac{\mathrm{mg}}{\mathrm{mL}}
\end{gathered}
$$

\section{Determining the overlap concentration for $\mathbf{P 2} 230$}

$M_{n}=231,500, M_{w}=442,300$ and $R_{g}=36.7 n m$, and $c^{*}=3.5 \mathrm{mg} / \mathrm{mL}$

$$
\begin{gathered}
\text { Volume of a polymer }=\frac{4}{3} \pi R_{g}^{3} \\
\text { Volume of a polymer }=\frac{4}{3} \pi\left(3.67 \cdot 10^{-6} \mathrm{~cm}\right)^{3}=2.07 \cdot 10^{-16} \mathrm{~cm}^{3} \\
\frac{1 \text { polymer }}{2.07 \cdot 10^{-16} \mathrm{~cm}^{3}} \cdot \frac{1 \mathrm{~mol}}{6.022 \cdot 10^{23} \text { polymers }} \cdot \frac{442,300 \mathrm{~g}}{\mathrm{~mol}}=0.0035 \frac{\mathrm{g}}{\mathrm{cm}^{3}}=3.5 \frac{\mathrm{mg}}{\mathrm{mL}}
\end{gathered}
$$




\section{Determining overlap concentration of $\mathbf{P} \mathbf{2}_{30}$}

Polymer $\mathbf{P} \mathbf{2}_{30}$ is also smaller than $10 \mathrm{~nm}$, so a linear regression is performed in the same manner as for polymer $\mathbf{P} \mathbf{1}_{20}$.

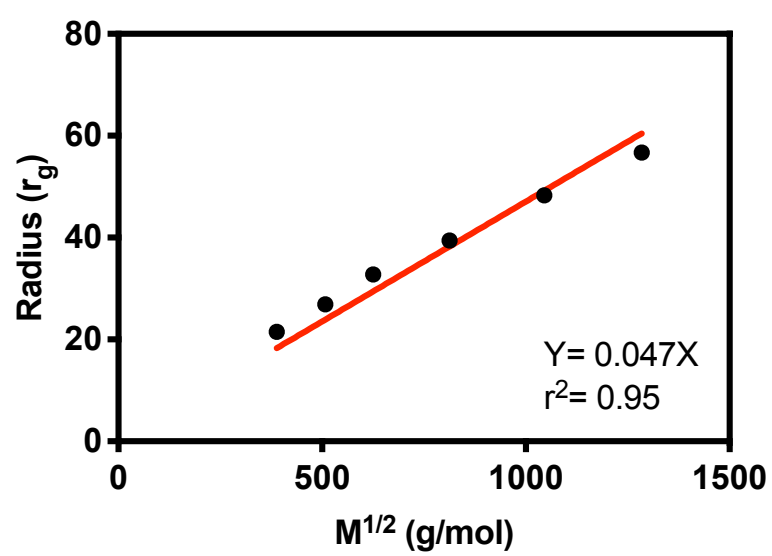

Figure S32: The radius of gyration plotted as a function of the square root of the molar mass.

For polymer $\boldsymbol{P} \mathbf{2}_{30}, M_{n}=31,700, M_{w}=40,200$, the calculated is $R_{g}=9.42 \mathrm{~nm}$.

$$
\begin{gathered}
\text { Volume of a polymer }=\frac{4}{3} \pi R_{\mathrm{g}}^{3} \\
\text { Volume of a polymer }=\frac{4}{3} \pi\left(9.42 \cdot 10^{-7} \mathrm{~cm}\right)^{3}=3.94 \cdot 10^{-18} \mathrm{~cm}^{3} \\
\frac{1 \text { polymer }}{3.94 \cdot 10^{-18} \mathrm{~cm}^{3}} \cdot \frac{1 \mathrm{~mol}}{6.022 \cdot 10^{23} \text { polymers }} \cdot \frac{40,200 \mathrm{~g}}{\mathrm{~mol}}=0.0169 \frac{\mathrm{g}}{\mathrm{cm}^{3}}=16.9 \frac{\mathrm{mg}}{\mathrm{mL}}
\end{gathered}
$$




\section{Single Molecule Force Spectroscopy}

Polymer $\mathbf{P} \mathbf{3}_{280}$ was used for force spectroscopy according to previously reported methods.

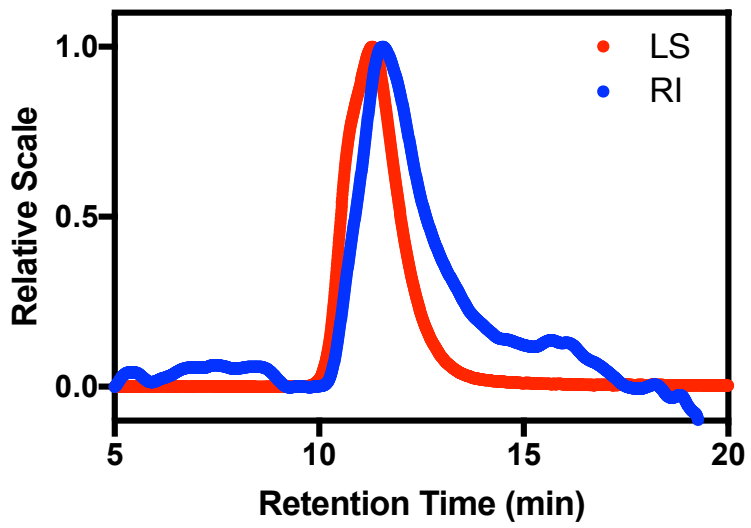

Figure S33: GPC data for $\mathbf{P 3}_{\mathbf{2 8 0}}$.

The extension curves were fit to the extended freely jointed chain model following previously published procedures. One plateau was observed in SMFS force curves for P3280 (Table S4). The average $\mathrm{F}^{\star}$ was $1417 \pm 67 \mathrm{pN}$ (Figure S32), while the literature value of $\mathrm{F}^{*}$ for $\mathrm{gDCC}$ is $\sim 1330 \mathrm{pN},{ }^{1 \mathrm{~b}}$ within the margin of error.

Table S4: SMFS data list for $\mathrm{P}_{2} 28$.

\begin{tabular}{|c|c|c|c|c|c|c|}
\hline & $\begin{array}{l}\text { gDCC } \\
\text { content }\end{array}$ & $\begin{array}{l}\mathrm{F}^{*} \text { (gDCC ring- } \\
\text { opening) }\end{array}$ & L1 (nm) & L2 (nm) & L2/L1 & F max \\
\hline P3280-1 & 0.6 & 1258.42 & 256.68 & 291.59 & 1.14 & 2290 \\
\hline $\mathbf{P 3}_{280-2}$ & 0.6 & 1383.89 & 218.28 & 249.43 & 1.14 & 2398 \\
\hline $\mathrm{P}_{280}=3$ & 0.6 & 1483.16 & 426.99 & 481.67 & 1.13 & 2065 \\
\hline $\mathrm{P}_{280}-4$ & 0.6 & 1476.53 & 487.41 & 550.95 & 1.13 & 2525 \\
\hline$P 3_{280}-5$ & 0.6 & 1394.61 & 407.62 & 465.26 & 1.14 & 2678 \\
\hline$P 3_{280}-6$ & 0.6 & 1474.52 & 621.22 & 688.17 & 1.11 & 1877 \\
\hline P3280-7 & 0.6 & 1441.44 & 525.22 & 588.11 & 1.12 & 2695 \\
\hline P3280-8 & 0.6 & 1381.84 & 197.95 & 216.74 & 1.09 & 2008 \\
\hline P3280-9 & 0.6 & 1432.42 & 487.46 & 551.56 & 1.13 & 2158 \\
\hline P3280-10 & 0.6 & 1439.11 & 392.16 & 431.11 & 1.10 & 1882 \\
\hline Avg & & 1416.59 & & & 1.12 & \\
\hline Std dev & & 67.11 & & & 0.02 & \\
\hline
\end{tabular}




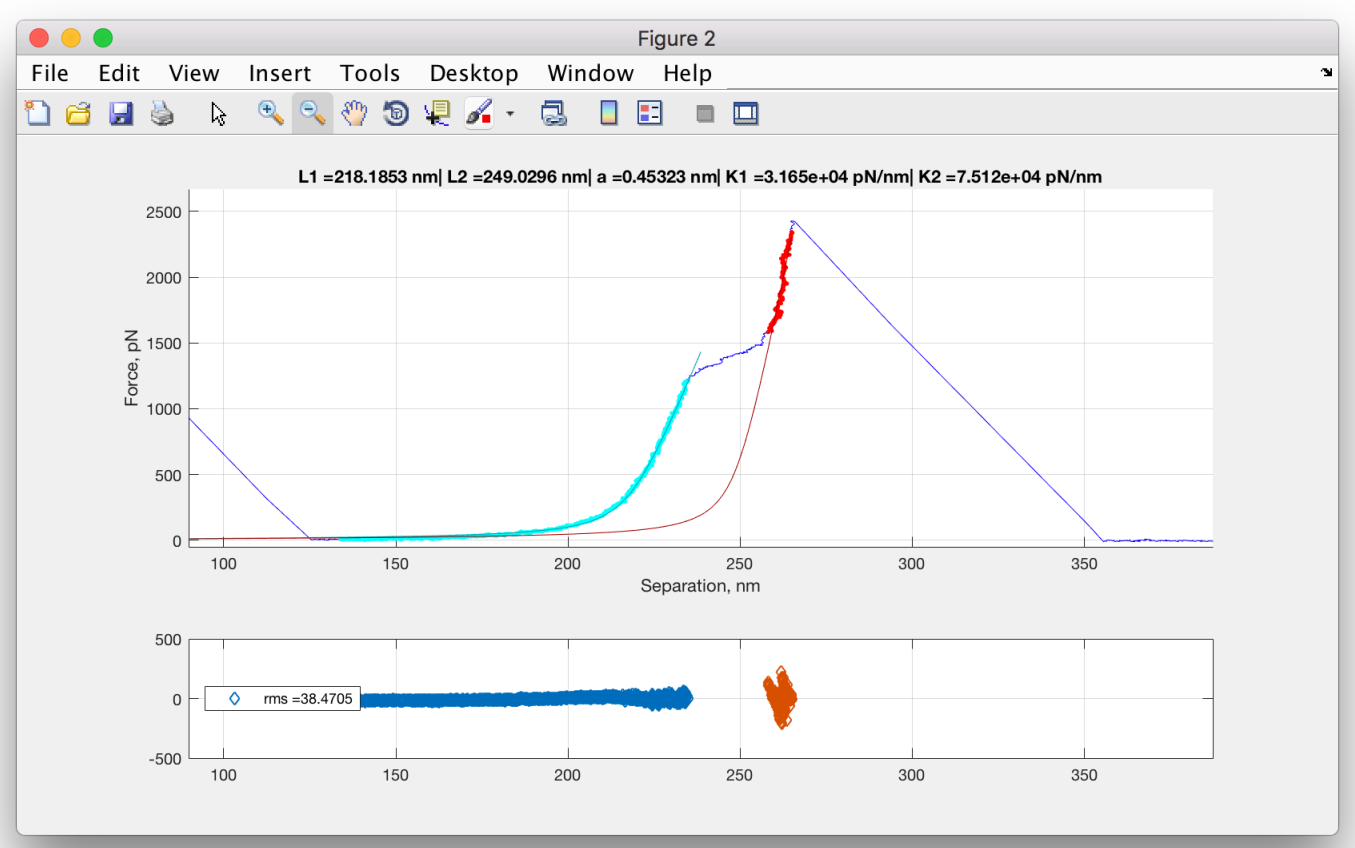

Figure S34: A complete force curve for $\mathbf{P 3}_{280}$ with fits to contour length before (L1) and after (L2) the plateau corresponding to the ring-opening of gDCC. The maximum force achieved is around $2400 \mathrm{pN}$, and no additional plateau for epoxide isomerization is observed.

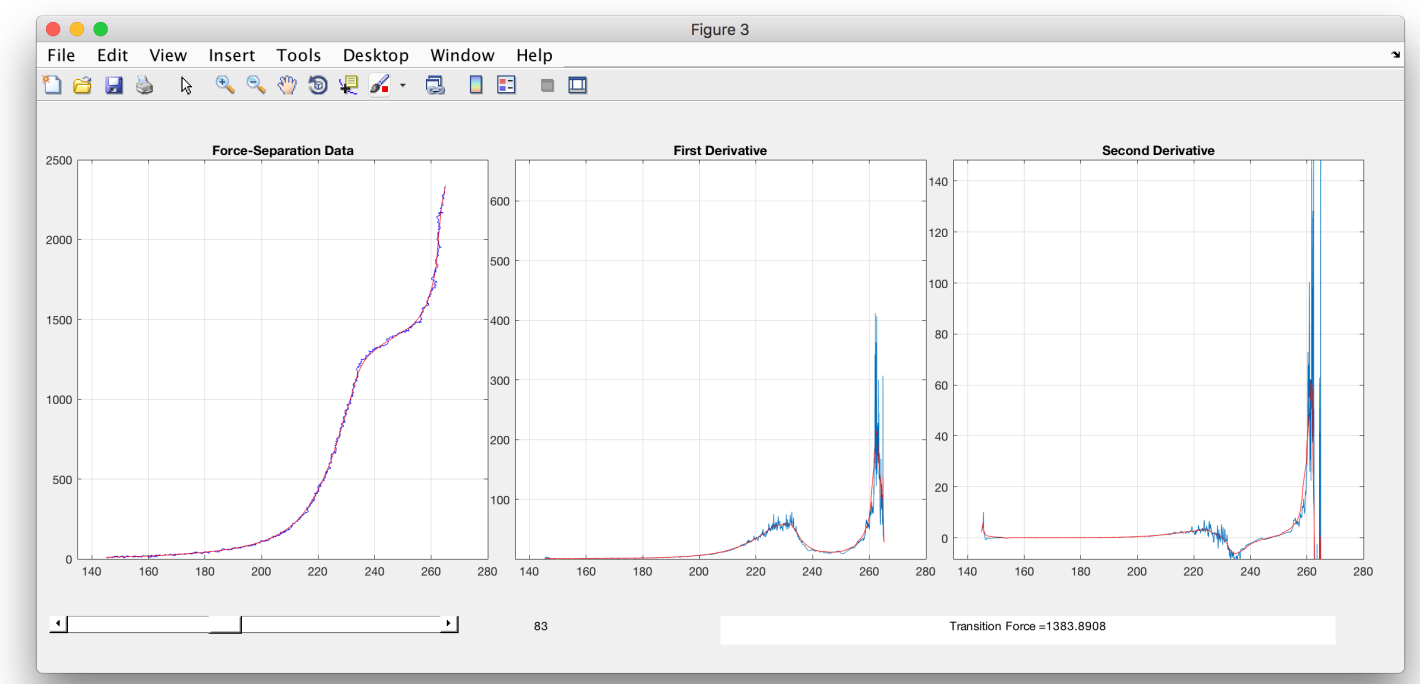

Figure S35: $\mathrm{F}^{\star}$ for $\mathrm{gDCC}$ ring-opening is determined by the inflection point of the force-distance curve for a representative polymer $\mathbf{P} \mathbf{3}_{\mathbf{2}}$, which is found by fitting to the first and second derivative. This process is described in detail elsewhere. ${ }^{1 a}$ 
The experimentally measured change in contour length was also compared to the theoretical prediction for the ring opening of gDCC using Equation 6:

$$
\frac{L_{f}}{L_{i}}=\frac{\left(L_{2,3-\text { dichloralkene }} \chi_{g D C C}\right)+\left(L_{\text {epoxy } \left.C O D^{*} \chi_{\text {epoxy } C O D}\right)}\right.}{\left(L_{g D C C} \chi_{g D C C}\right)+\left(L_{\text {epoxy }} \operatorname{COD}^{*} \chi_{\text {epoxy }} \operatorname{COD}\right)}
$$

where $L$ is the end to end distance determined from COGEF modeling ${ }^{7}$ and $X$ is the mole fraction determined by ${ }^{1} \mathrm{H}$ NMR. Results are summarized in Table 55 .

Table S5: Theoretically determined extension ratios for $\mathbf{P} \mathbf{3}_{280}$.

\begin{tabular}{cccc}
\hline & $\begin{array}{c}\text { gDCC content } \\
\left({ }^{1} \mathrm{H} \text { NMR) }\right.\end{array}$ & $\begin{array}{c}\mathbf{L}_{\mathfrak{f}} / \mathbf{L}_{\mathbf{i}} \\
(\mathrm{SMFS})\end{array}$ & $\begin{array}{c}\mathbf{L}_{\mathrm{f}} / \mathbf{L}_{\mathbf{i}} \\
(\mathrm{COGEF})\end{array}$ \\
\hline P3280 & 0.60 & $1.12 \pm 0.02$ & 1.10 \\
\hline
\end{tabular}

The mole fraction of gDCC in $\mathbf{P 3}_{\mathbf{2 8 0}}$ is determined by ${ }^{1} \mathrm{H}$ NMR (Figures S34 and S35).

Fraction $g D C C=\frac{\left(\frac{H_{g D C C \text { vinyl }}}{2}\right)}{\frac{H_{g D C C \text { vinyl }}+H_{\text {epoxyCoD vinyl }}}{2}}=0.60$

$\mathrm{H}_{\text {vinyl gDCC }}=\int 5.548-5.339=1.93$

$H_{\text {vinyl epoxy COD }}=\int 5.346-5.151=0.65$ 


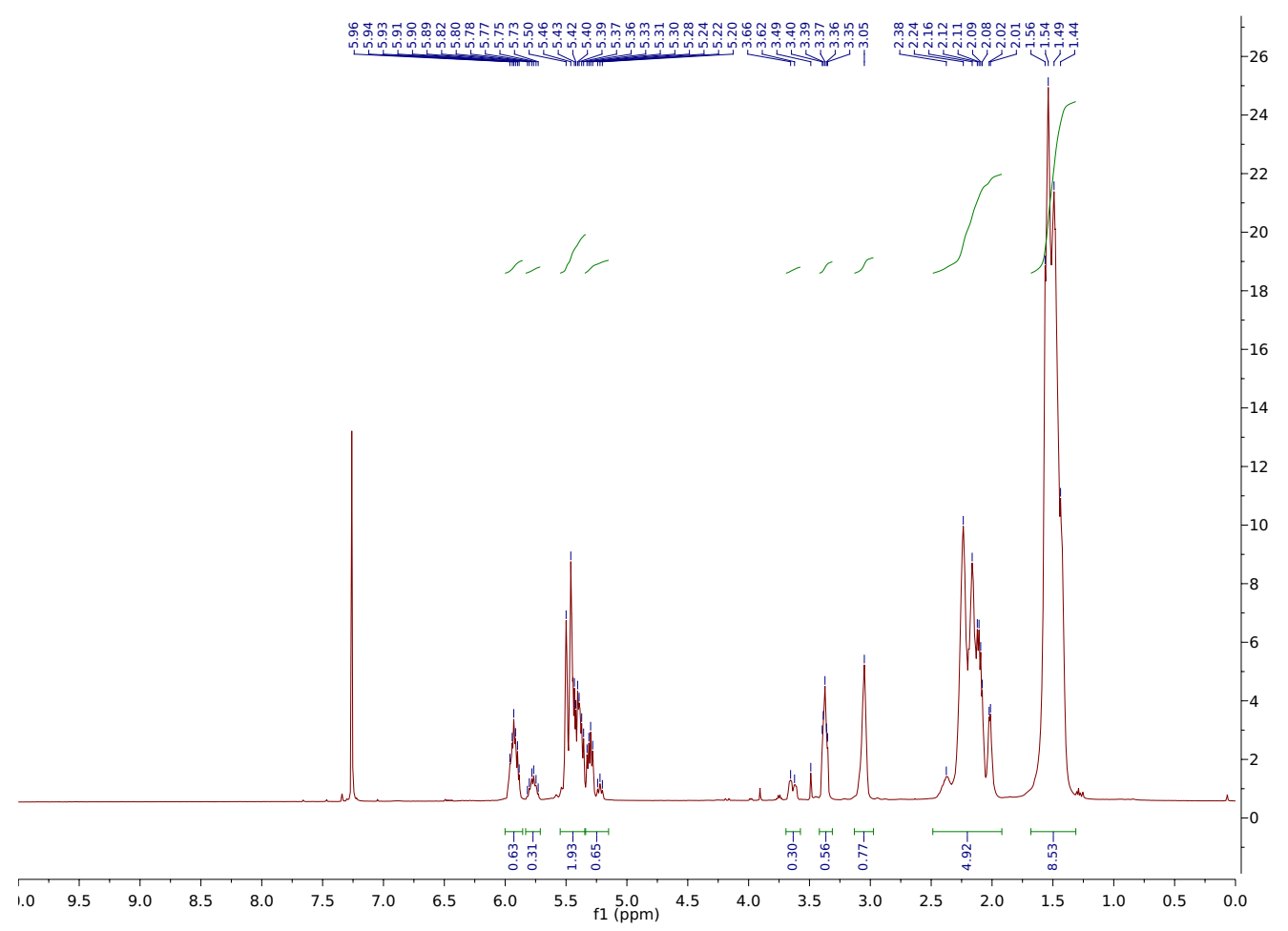

Figure S36: ${ }^{1} \mathrm{H}$ NMR of $\mathbf{P 3}_{\mathbf{2 8 0}}\left(500 \mathrm{MHz}, \mathrm{CDCl}_{3}\right)$.

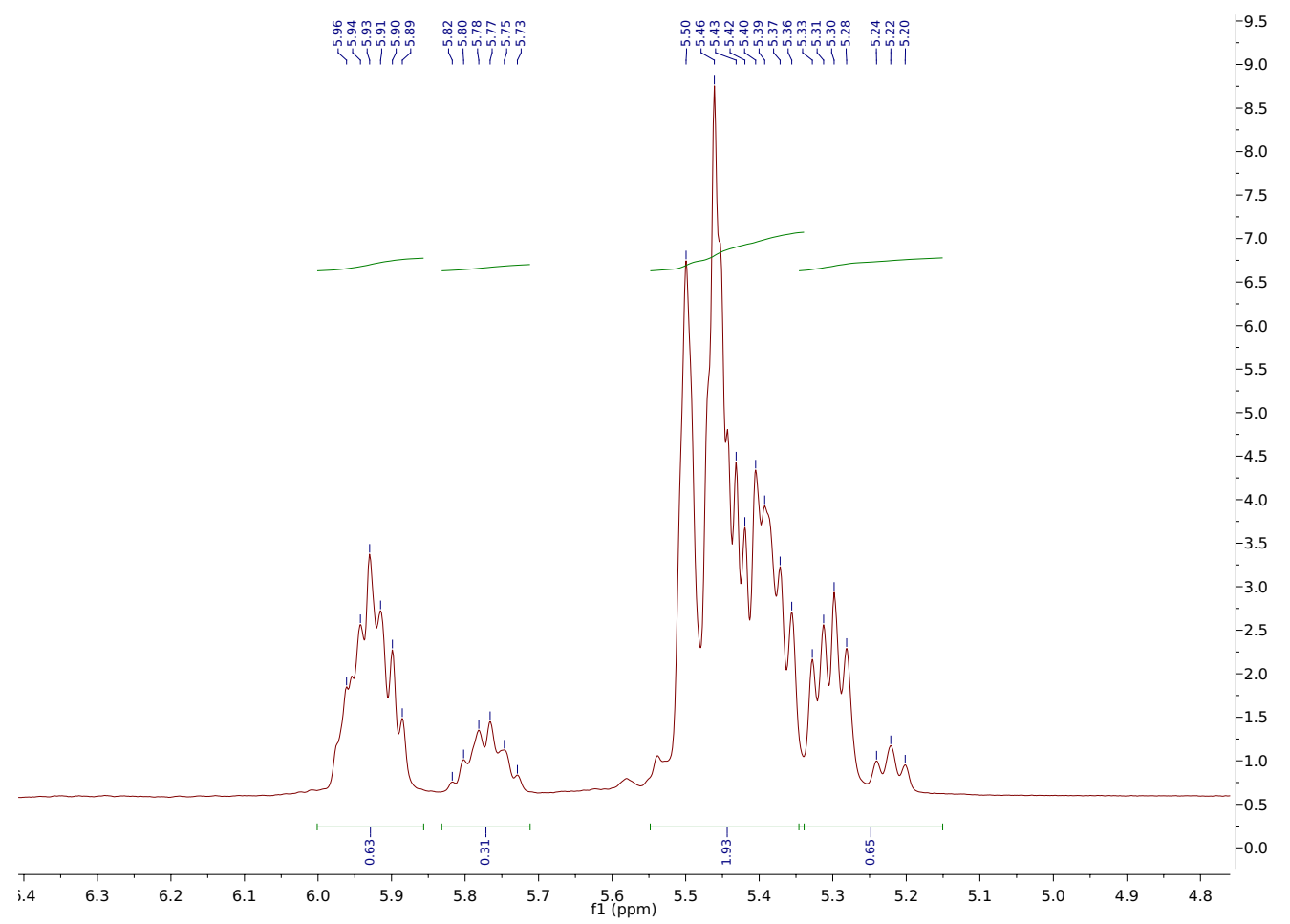

Figure S37: The region of the ${ }^{1} \mathrm{H}$ NMR spectra integrated to determine gDCC content of $\mathbf{P 3}_{\mathbf{2 8 0}}$ $\left(500 \mathrm{MHz}, \mathrm{CDCl}_{3}\right)$. 
Force-free contour lengths were determined with Spartan '16 modeling software using semi-empirical AM1 level of theory. Methods are detailed elsewhere, ${ }^{1 \mathrm{~b}}$ but briefly, the end-to-end distance is constrained in increments of $\sim 0.2 \AA$ and the energy is calculated for each distance. The relative energy is plotted as a function of distance and fit to a quadratic. The first derivative of the fit gives a linear relationship between force and distance. Contour length is calculated as the length at zero force. Each monomer contour length is determined three times and the average is used to calculate theoretical extension.

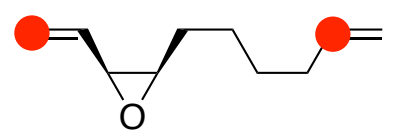

Figure S38: The structure modeled to determine the contour length for the cis-epoxide monomer. The constraint was between the atoms indicated with red circles.
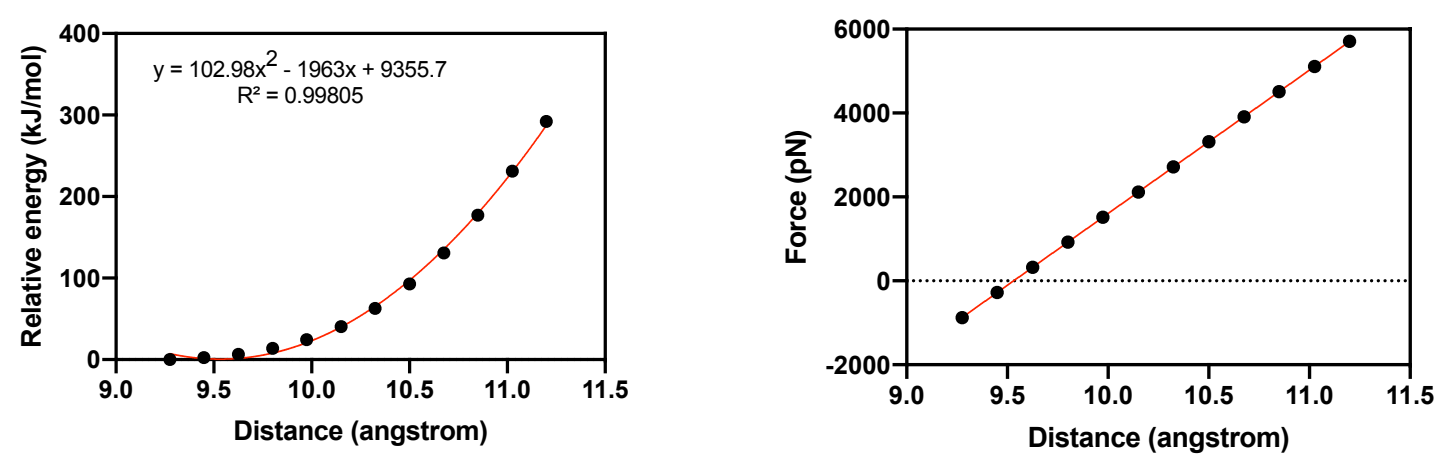

Figure S39: A representative COGEF model of contour length for cis-epoxide monomer. Left: Quadratic fit to energy vs. distance. Right: The force-distance plot obtained from the first derivative of the quadratic fit. The average of three experiments gave a contour length of $9.52 \AA$, or $0.952 \mathrm{~nm}$.

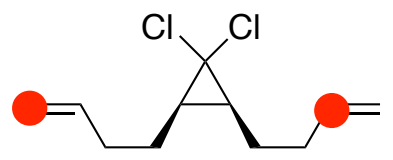

Figure S40: The structure modeled to determine the contour length for the cis-gDCC monomer. The constraint was between the atoms indicated with red circles.
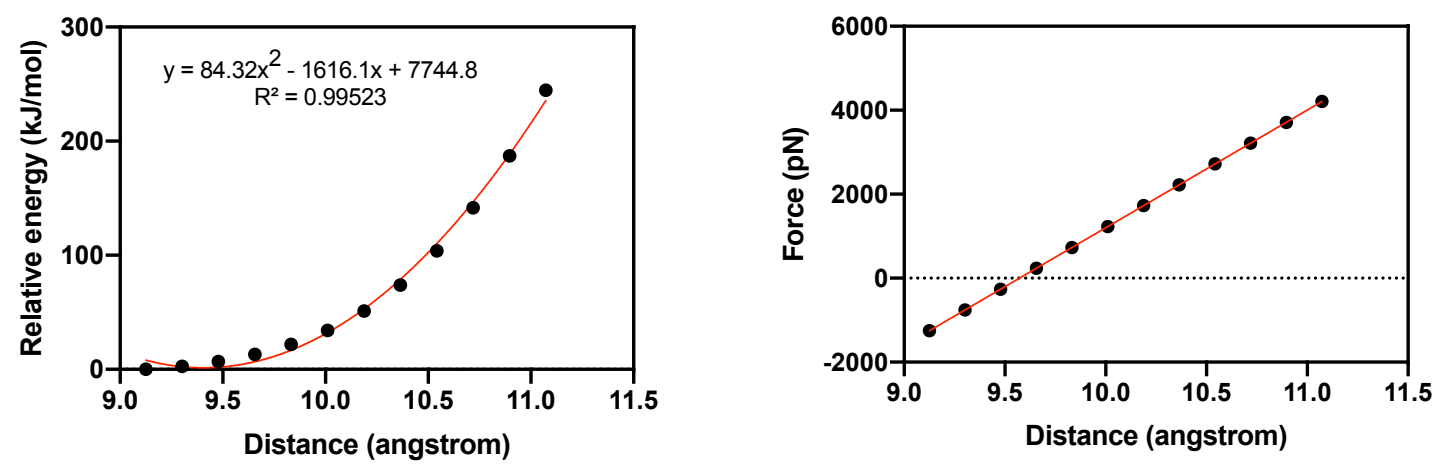
Figure S41: A representative COGEF model of contour length for cis-gDCC monomer. Left: Quadratic fit to energy vs. distance. Right: The force-distance plot obtained from the first derivative of the quadratic fit. The average of three experiments gave a contour length of $9.45 \AA$, or $0.945 \mathrm{~nm}$. Figure S42: The structure modeled to determine the contour length for (Z) 2,3-dichloroalkene. The<smiles>C=CC/C=C(\Cl)C(Cl)CCC=O</smiles>

constraint was between the atoms indicated with red circles.
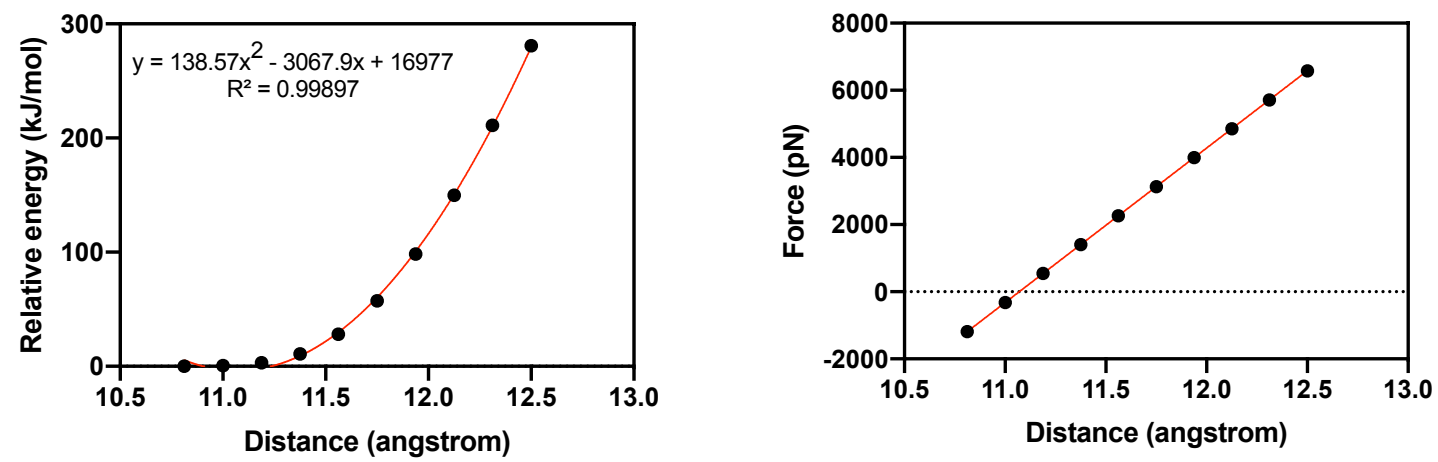

Figure S43: A representative COGEF model of contour length for (Z) 2,3-dichloroalkene product. Left: Quadratic fit to energy vs. distance. Right: The force-distance plot obtained from the first derivative of the quadratic fit. The average of three experiments gave a contour length of $11.06 \AA$, or $1.106 \mathrm{~nm}$. 


\section{Rate Constant Calculation}

The upper limit of the reaction rate was calculated from the force curve P3280-7. The timestamps recorded with the force-distance data were used to determine that time interval required for the force to go from $2500 \mathrm{pN}$ to $2600 \mathrm{pN}$ is $0.019 \mathrm{~s}$. We conservatively estimate that less than $10 \%$ of the mechanophores have reacted (or evidence of the reaction would be clearly visible in the force-distance curve), and so the force-coupled rate constant of the reaction is less than $5 \mathrm{~s}^{-1}(0.1 / 0.019$ s) at a force of $2500 \mathrm{pN}$.

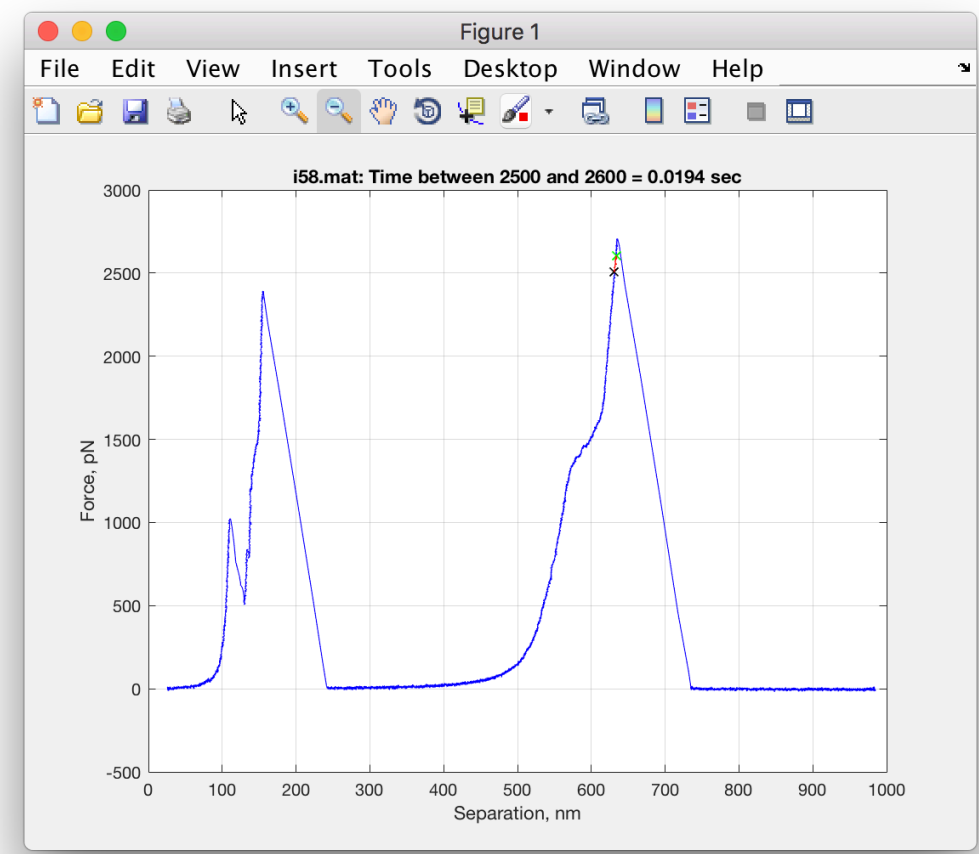

Figure S44: The time interval between $\mathrm{F}=2500 \mathrm{pN}$ and $2600 \mathrm{pN}$ was determined with timestamps collected with SMFS data using software written in Matlab. 


\section{NMR Spectra}

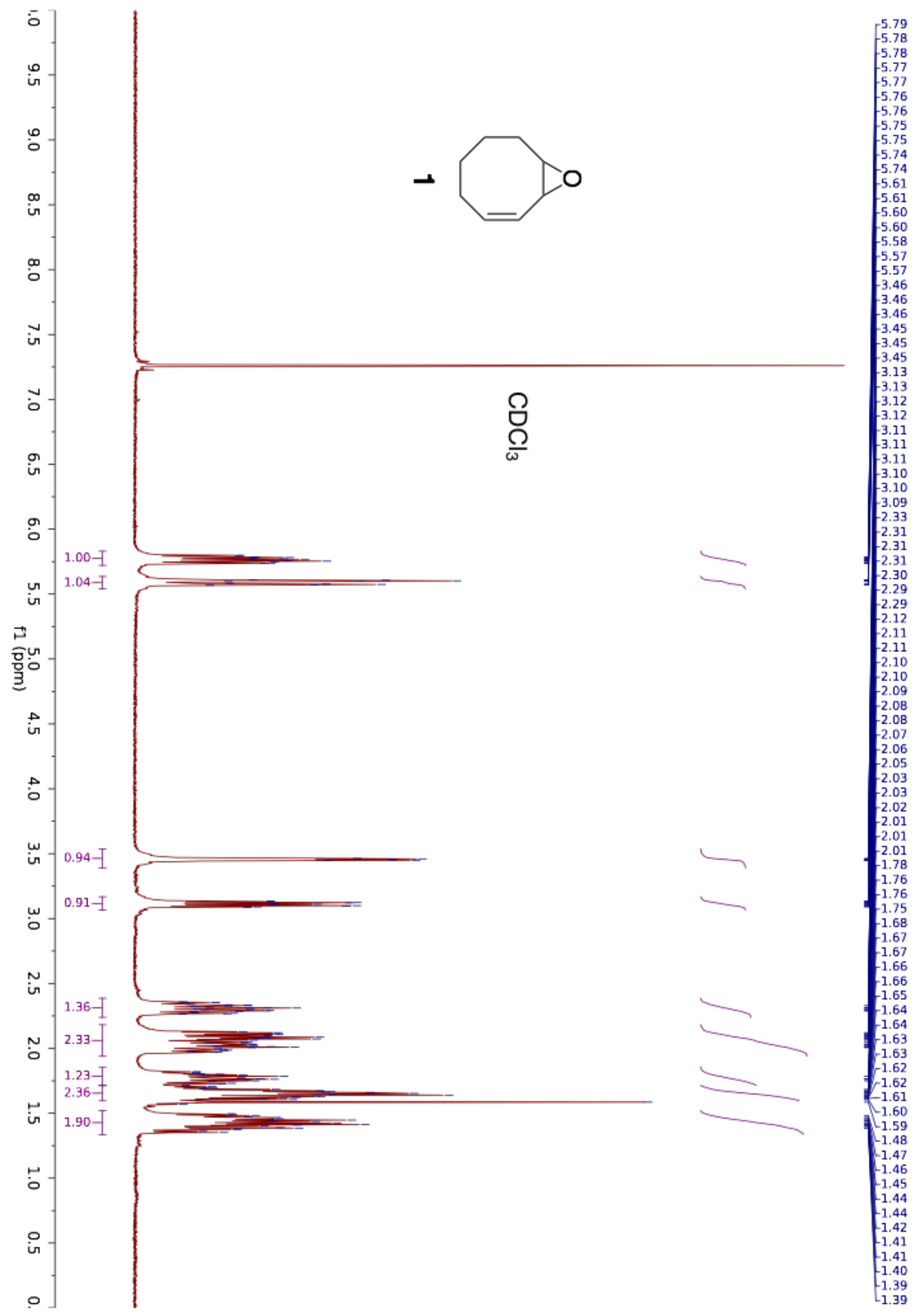




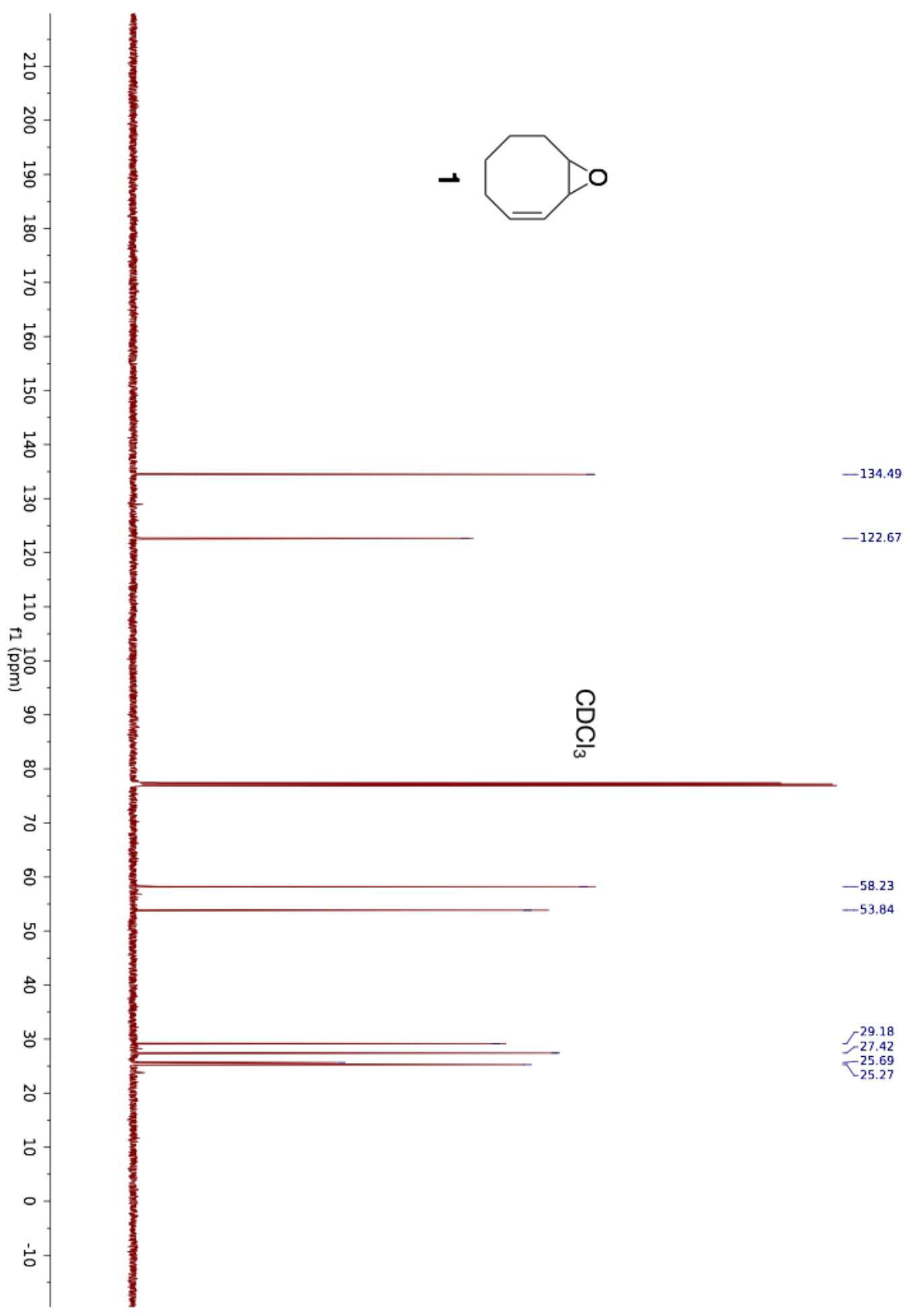




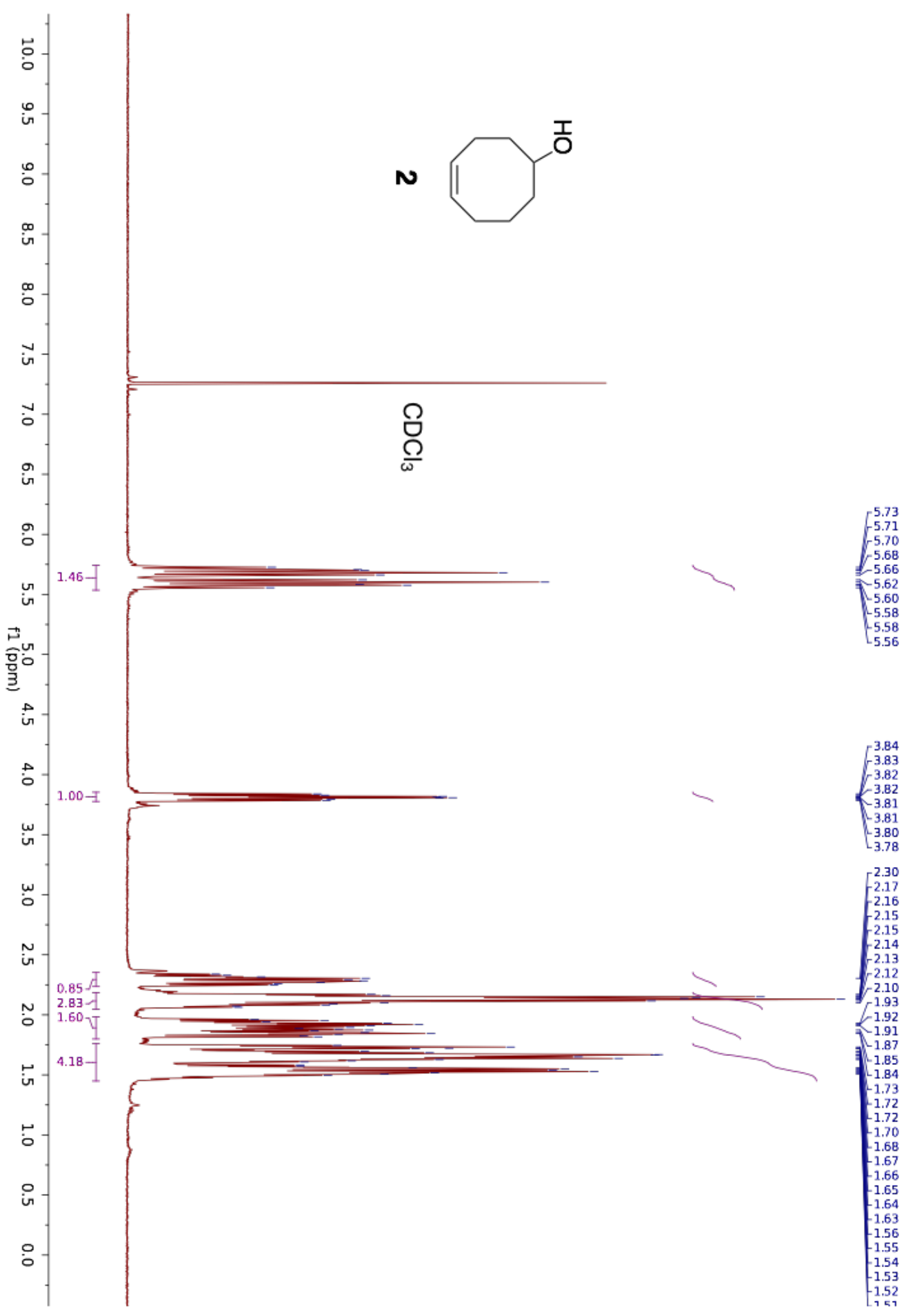




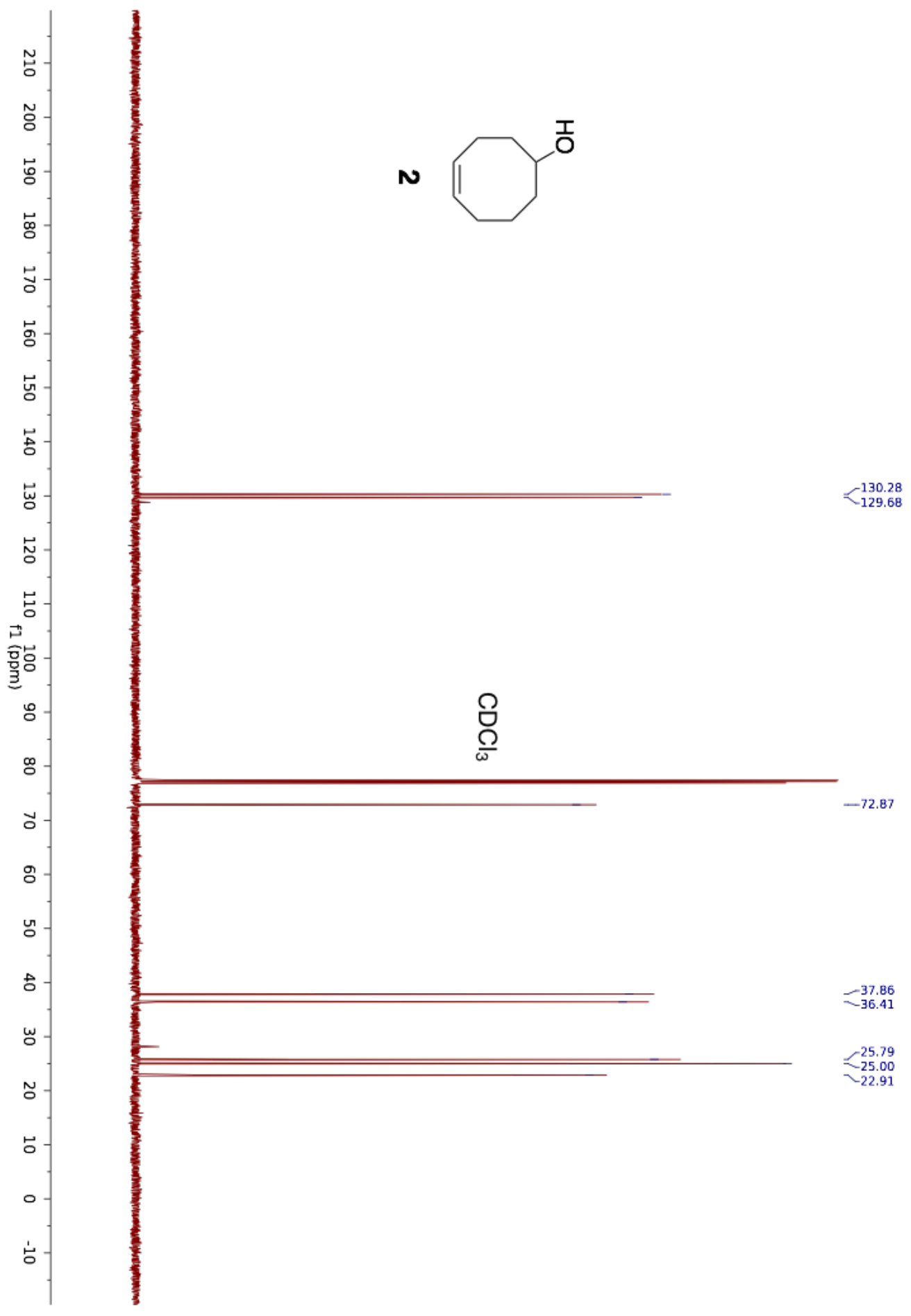




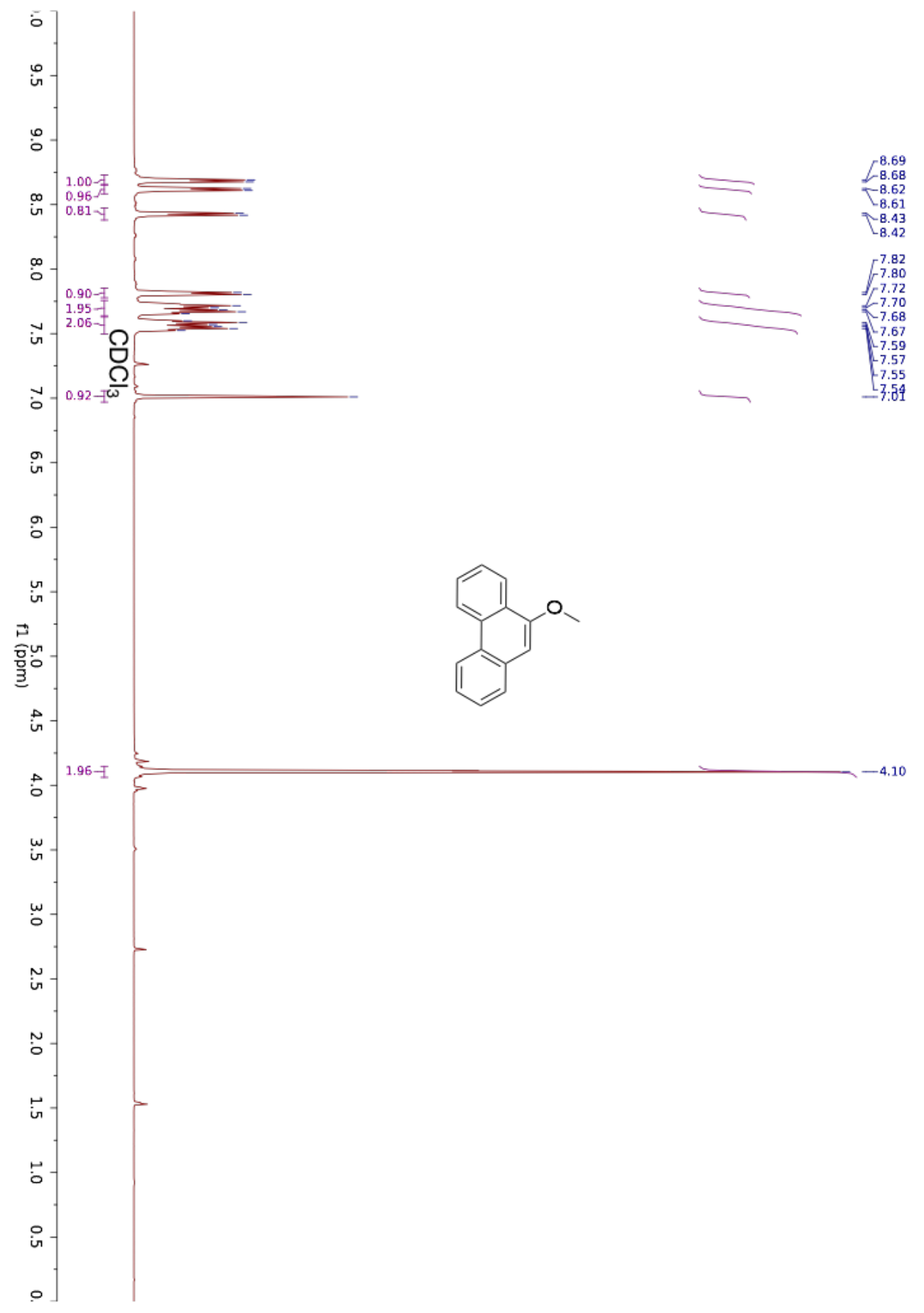




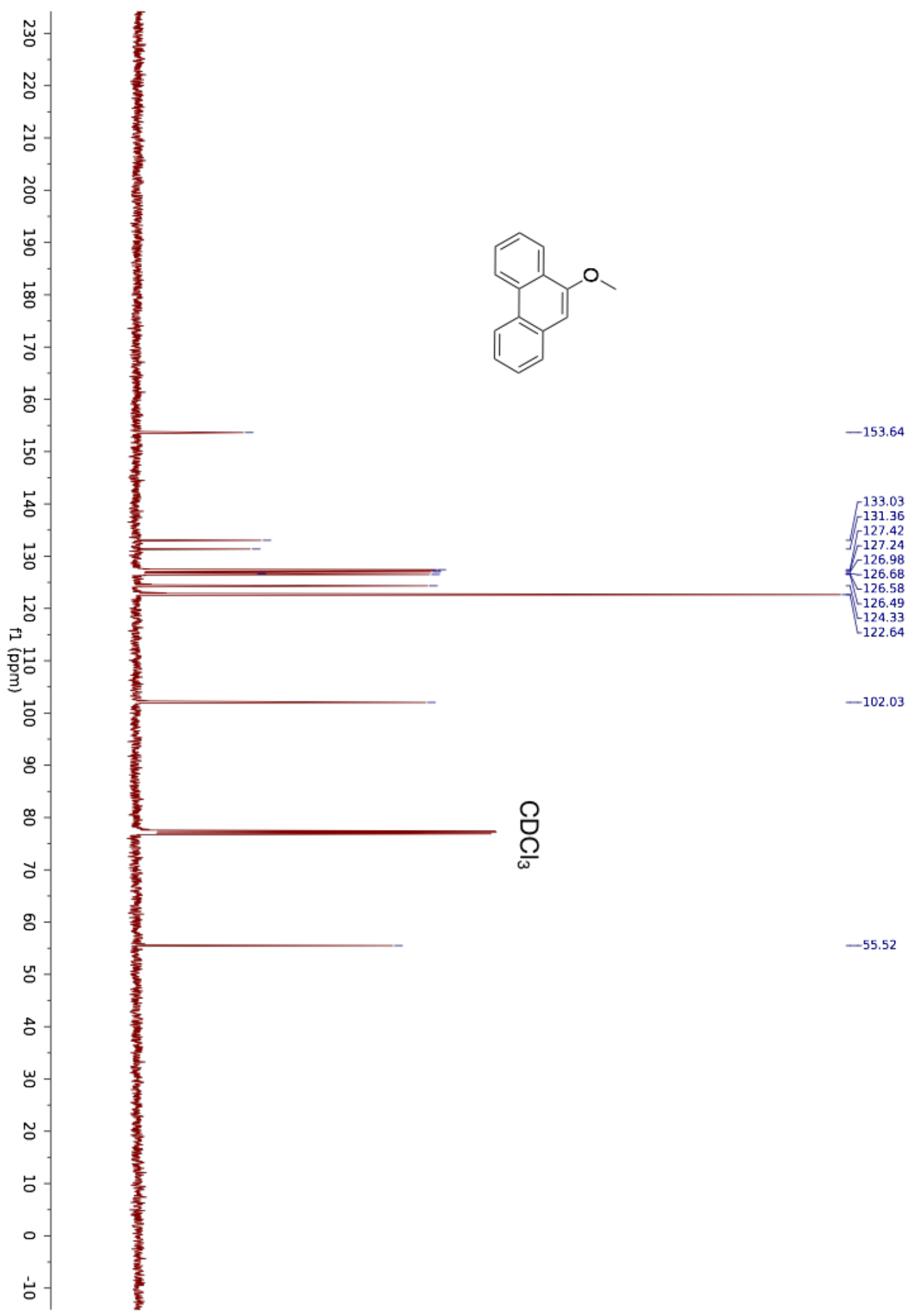




\section{References}

1. (a) Gossweiler, G. R.; Kouznetsova, T. B.; Craig, S. L. Force-rate characterization of two spiropyran-based molecular force probes. Journal of the American Chemical Society 2015, 137, 6148-6151; (b) Klukovich, H. M.; Kouznetsova, T. B.; Kean, Z. S.; Lenhardt, J. M.; Craig, S. L. A backbone leverarm effect enhances polymer mechanochemistry. Nat. Chem. 2013, 5, 110-114; (c) Wu, D.; Lenhardt, J. M.; Black, A. L.; Akhremitchev, B. B.; Craig, S. L. Molecular stress relief through a force-induced irreversible extension in polymer contour length. Journal of the American Chemical Society 2010, 132, 1593615938.

2. (a) Hutter, J. L.; Bechhoefer, J. Calibration of atomic - force microscope tips. Review of Scientific Instruments 1993, 64, 1868-1873; (b) Cook, S. M.; Schäffer, T. E.; Chynoweth, K. M.; Wigton, M.; Simmonds, R. W.; Lang, K. M. Practical implementation of dynamic methods for measuring atomic force microscope cantilever spring constants. Nanotechnology 2006, 17, 2135. 3. $\quad$ Clark, P. G.; Guidry, E. N.; Chan, W. Y.; Steinmetz, W. E.; Grubbs, R. H. Synthesis of a molecular charm bracelet via click cyclization and olefin metathesis clipping. Journal of the American Chemical Society 2010, 132, 34053412.

4. Jang, K. S.; Shin, D. S.; Srisook, E.; Song, H.-C.; Chi, D. Y. Versatile functionalization of electron rich-fused heterocyclic arenes via electrophilic aromatic addition reaction and their applications. Tetrahedron 2016, 72, 51065114.

5. Wang, J.; Piskun, I.; Craig, S. L. Mechanochemical strengthening of a multi-mechanophore benzocyclobutene polymer. ACS Macro Lett. 2015, 4, 834837.

6. Ramirez, A. L.; Kean, Z. S.; Orlicki, J. A.; Champhekar, M.; Elsakr, S. M.; Krause, W. E.; Craig, S. L. Mechanochemical strengthening of a synthetic polymer in response to typically destructive shear forces. Nat. Chem. 2013, 5, 757-761.

7. Beyer, M. K. The mechanical strength of a covalent bond calculated by density functional theory. The Journal of Chemical Physics 2000, 112, 73077312 . 